\title{
Can explicit convection improve modelled dust in summertime West Africa?
}

\author{
Alexander J. Roberts ${ }^{1}$, Margaret J. Woodage ${ }^{2}$, John H. Marsham ${ }^{1,3}$, Ellie J. Highwood ${ }^{2}$, Claire L. Ryder ${ }^{2}$, \\ Willie McGinty ${ }^{4}$, Simon Wilson ${ }^{4}$, and Julia Crook ${ }^{1}$ \\ ${ }^{1}$ School of Earth and Environment, University of Leeds, LS2 9JT, Leeds, UK \\ ${ }^{2}$ Department of Meteorology, University of Reading, RG6 6BB, Reading, UK \\ ${ }^{3}$ National Centre for Atmospheric Science, University of Leeds, Leeds, UK \\ ${ }^{4}$ NCAS-CMS, Department of Meteorology, University of Reading, Reading, UK
}

Correspondence: Alexander J. Roberts (a.j.roberts1@leeds.ac.uk)

Received: 1 November 2017 - Discussion started: 4 January 2018

Revised: 17 May 2018 - Accepted: 17 May 2018 - Published: 28 June 2018

\begin{abstract}
Global and regional models have large systematic errors in their modelled dust fields over West Africa. It is well established that cold-pool outflows from moist convection (haboobs) can raise over $50 \%$ of the dust over parts of the Sahara and Sahel in summer, but parameterised moist convection tends to give a very poor representation of this in models. Here, we test the hypothesis that an explicit representation of convection in the Met Office Unified Model (UM) improves haboob winds and so may reduce errors in modelled dust fields. The results show that despite varying both grid spacing and the representation of convection there are only minor changes in dust aerosol optical depth (AOD) and dust mass loading fields between simulations. In all simulations there is an AOD deficit over the observed central Saharan dust maximum and a high bias in AOD along the west coast: both features are consistent with many climate (CMIP5) models. Cold-pool outflows are present in the explicit simulations and do raise dust. Consistent with this, there is an improved diurnal cycle in dust-generating winds with a seasonal peak in evening winds at locations with moist convection that is absent in simulations with parameterised convection. However, the explicit convection does not change the AOD field in the UM significantly for several reasons. Firstly, the increased windiness in the evening from haboobs is approximately balanced by a reduction in morning winds associated with the breakdown of the nocturnal low-level jet (LLJ). Secondly, although explicit convection increases the frequency of the strongest winds, they are still weaker than observed, especially close to the observed summertime Saharan dust maxi-
\end{abstract}

mum: this results from the fact that, although large mesoscale convective systems (and resultant cold pools) are generated, they have a lower frequency than observed and haboob winds are too weak. Finally, major impacts of the haboobs on winds occur over the Sahel, where, although dust uplift is known to occur in reality, uplift in the simulations is limited by a seasonally constant bare-soil fraction in the model, together with soil moisture and clay fractions which are too restrictive of dust emission in seasonally varying vegetated regions. For future studies, the results demonstrate (1) the improvements in behaviour produced by the explicit representation of convection, (2) the value of simultaneously evaluating both dust and winds and (3) the need to develop parameterisations of the land surface alongside those of dust-generating winds.

\section{Introduction}

During the summer season the Sahara is the world's largest source of mineral dust (Ginoux et al., 2012; Prospero et al., 2002) and representations of dust are known to improve numerical weather prediction (NWP) models (Haywood et al., 2005; Tompkins et al., 2005; Rodwell and Jung, 2008), although the accuracy of dust forecasts remains limited (Chaboureau et al., 2016; Huneeus et al., 2016; Terradellas et al., 2016). Dust is also a prognostic variable in several climate models, although its value has been questioned due to the poor performance of the models in representing dust variability (Evan et al., 2014). There is, therefore, a need to 
improve dust models across timescales and a need to improve the representation of both the land surface that emits dust and dust-generating winds. For winds it is known that rare, high wind speed events are disproportionately important for raising dust (Cowie et al., 2015) and that a poor representation of cold-pool outflows from moist convection (haboobs: Roberts and Knippertz, 2012) is one major limitation of summertime winds in current models for the Sahara and Sahel (Marsham et al., 2011; Knippertz and Todd, 2010). Haboobs can range in size from tens to hundreds of kilometres across and rare, large events can be some of the largest single uplift events in West Africa (here defined as the United Nations subregion of West Africa and Algeria, Morocco, Tunisia and Western Sahara; Roberts and Knippertz, 2014). Although often considered a Sahelian phenomenon (in West Africa), haboobs were shown by Marsham et al. (2013) and Allen et al. (2013) to be observed commonly at Bordj Badji Mokhtar in the central Sahara $\left(21.38^{\circ} \mathrm{N}, 0.92^{\circ} \mathrm{E}\right)$ during June of 2011 . Rainfall retrievals (Tropical Rainfall Measuring Mission) also indicate that precipitating clouds are present north of the position of the analysed intertropical discontinuity (as much as $5^{\circ}$ ) at times of monsoon surges (Fig. 9 in Roberts et al., 2015). This is important, not because of the likelihood of rainfall reaching the surface, but because (consistent with Marsham et al., 2013; Allen et al., 2013; Trzeciak et al., 2017), cold pools and haboobs can be generated north of the analysed monsoon flow in a region with a deep dry boundary layer and deflatable surface soil (the Sahara).

Several meteorological processes are known to raise mineral dust. Synoptic-scale systems (Johnson and Osborne, 2011) and the breakdown of nocturnal low-level jets (Knippertz, 2008; Fiedler et al., 2013) are of sufficiently large scale to be captured by many models (Woodage et al., 2010; Johnson et al., 2011). However, it is estimated that dust raised by convectively generated cold-pool outflows contribute over $50 \%$ of the summertime uplift in some areas of the Sahel and Sahara (Marsham et al., 2013; Allen et al., 2013, 2014; Heinold et al., 2013) and may explain the seasonal cycle of dust in the region (Marsham et al., 2008). The parameterised representation of convection in global models can make haboobs essentially non-existent (Marsham et al., 2011) and, consistent with this, data assimilation has shown that an NWP model with prognostic dust underestimates dust in regions of observed haboobs (Pope et al., 2016). The comparison of observed near-surface winds with meteorological reanalyses in key dust uplift areas (Largeron et al., 2015; Roberts et al., 2017) highlights that even such analyses, which are constrained by assimilation of available observations (and often used as de-facto observations), have large systematic biases. In particular, the distribution of wind speed in analyses misses the high wind speed tail, the seasonal and diurnal cycles have amplitudes that are too small and the seasonal evening peak in winds associated with cold pools is missing. A common feature of many previously conducted evaluations of models or analyses is that they evaluate only the dust (usually AOD, e.g. Johnson, 2011; Párez et al., 2011) or the winds (e.g. Largeron et al., 2015; Roberts et al., 2017) and not both the dust emission and surface winds. This is despite it being known that there are likely to be systematic biases in both model winds and dust. Without an investigation of the winds alongside the dust it is impossible to judge whether a successful replication of dust fields are a result of compensating errors or whether all process involved (including transport and deposition) are correctly represented.

Recent modelling work has attempted to address the role of haboobs in models by resolving convection explicitly with high-resolution simulations (Cascade; Birch et al., 2014; Pearson et al, 2014) and applying an offline dust model (Heinold et al., 2013); this highlighted the importance of convective cold pools as well as the representation of nearsurface night-time stability. Despite the improved diurnal cycle in windiness associated with cold pools using this approach, it is important to recognise that simulations capable of producing organised convective storms are not automatically able to represent near-surface winds of cold pools. Simulated cold pools are likely to differ from real-world examples in terms of size, duration and wind speed. Another approach has been the development and application of a haboob parameterisation, in which additional low-level winds are added that are linked to mass fluxes from the convection scheme (Pantillon et al., 2015, 2016). This approach led to an improved agreement between the potential dust uplift in convection-permitting simulations and those with parameterised convection. However, this method obviously does not seek to correct the diurnal cycle bias in rainfall (where peak rain occurs close to midday in parameterised convection simulations, and in the evening in convection permitting simulations and in reality) or evaluate winds from convectionpermitting simulations against observations in any detail. Chaboureau et al. (2016) compared near-surface winds and prognostic dust from in-line simulations with both explicit and parameterised convection. They show some success in increasing the occurrence of strong winds in the evening (haboobs) when explicitly representing convection, and in improving the dust AOD biases relative to observations by increasing AOD values in the southern Sahara and northern Sahel. They also show improvements to the meridional AOD gradient to the west of the Sahara. However, the variability in AOD at specific sites, including very high values associated with convectively active African easterly waves, is still underrepresented even with explicit convection. In Chaboureau et al. (2016) simulations were re-initialised daily, preventing the modification of the large-scale monsoon flow by convective storms (Marsham et al., 2011, 2013; Garcia Carreras et al., 2013). They also encompassed only part of the summer season (25 July-2 September 2006; Heinold et al., 2013; 1 June-30 July 2006; Pantillon et al., 2015 and 1-30 June 2011; Chaboureau et al., 2016) so do not show the full seasonal evolution and were not able to clearly demonstrate the 
impact of resolved versus parameterised convection in models that were otherwise identical.

The Saharan - West African Monsoon Multi-scale Analysis (SWAMMA) project simulations used in this study have a range of horizontal grid spacing $(4-40 \mathrm{~km})$ and have both convection-permitting and parameterised convection set-ups. They are performed over a full summer season (1 May30 September 2011) with a fully interactive mineral dust scheme. Although lateral boundary conditions are updated hourly, the size of the domain and duration of the runs means that away from boundaries model fields can diverge from the parent model, allowing the evolution of the hydrological and dust cycles in each simulation. The authors believe this to be the first reported study of large domain multi-day convectionpermitting simulations with prognostic dust over the Sahara and Sahel. The approach of using both dust AOD retrievals and observations of near-surface wind speed to evaluate simulations also makes this work novel and gives an unprecedented opportunity to attribute errors in dust uplift as well as in AOD magnitude and distribution. The arrangement of this paper is as follows: Sect. 2 describes the model set-up, experiments performed and observations used to validate the model. Results are presented in Sect. 3, in which model dust AODs, emissions, low-level winds and storm development are compared between the different models and with observations. Discussion of the results and conclusions follow in Sect. 4.

\section{Data and methods}

\subsection{Model set-up}

SWAMMA simulations use a limited-area version of the UK Met Office (UKMO) Unified Model (UM), based on the HadGEM3-RA regional climate model previously tested at various resolutions over Africa (Moufouma-Okia and Jones, 2015). The UM is designed to function across a wide range of spatial and temporal scales and is used for meteorology and climate research as well as operational numerical weather prediction. The UM (version 8.2 is used here) consists of a dynamical core (Davies et al., 2005; Staniforth et al., 2006) which describes evolution of the atmosphere as a non-hydrostatic, fully compressible fluid. Model levels are terrain which is close to the surface but relaxes to smooth, parallel levels at height. The model has a fixed Eulerian grid but utilises the semi-implicit, semi-Lagrangian time stepping to advect variables (allowing for mass conservation). Physics packages include a two-stream radiation code (Edwards et al., 2012), the Joint UK Land Environment Simulator (JULES) land surface exchange scheme (Best, 2005; Best et al., 2011), boundary layer turbulence (Lock and Edwards, 2012), cloud microphysics (Wilkinson, 2012) and convection (Stratton et al., 2009). The SWAMMA simulations use a limited area set-up with a domain encompassing all of West
Africa (approximately $0-35^{\circ} \mathrm{N}$ and $23^{\circ} \mathrm{W}-35^{\circ} \mathrm{E}$ ). Simulations are conducted at horizontal grid spacings of 4,12 and $40 \mathrm{~km}$, all having 70 levels in the vertical. The 12 and $40 \mathrm{~km}$ models have a rigid model lid at a height of $80 \mathrm{~km}$, while the $4 \mathrm{~km}$ version has a rigid lid at $40 \mathrm{~km}$ height. The differences in vertical spacing between the $4 \mathrm{~km}$ simulations and the rest of the simulations means that the height of the lowest model level is also different (approximately $2.5 \mathrm{~m}$ for the $4 \mathrm{~km}$ simulations and $10 \mathrm{~m}$ for the rest). Model levels are concentrated in the lower atmosphere to better represent meteorological processes. The simulations are initialised at the beginning of the simulation period on 1 May and run until the end of the simulation period without being reinitialised. As such the interior of the model is able to behave in a similar "free-running" way to regional climate simulations, and the model monsoon system is able to develop without the strict constraints of analysed conditions. This allows for the characteristics of the modelled monsoon to arise and highlight model errors that are likely present in other similarly constrained simulations. The lateral boundary conditions (horizontal winds and potential temperature) are updated every hour and produced by performing global simulations using the UM on an N216 ( 60 km) grid (also version 8.2). Global simulations are initialised every $6 \mathrm{~h}$ using European Centre for Medium-Range Weather Forecasts (ECMWF) operational analysis data. Sea surface temperatures for the limitedarea SWAMMA runs are updated every $6 \mathrm{~h}$ and obtained by regridding ECMWF operational analysis data (as above). Land surface features are handled by the JULES land surface exchange scheme with some features being described by invariant ancillary files (vegetation fraction) and others evolving due to simulated conditions (soil moisture). The UM configuration used for SWAMMA is not dissimilar to that used by the Cascade simulations (a series of simulations over West Africa for a 40-day period in summer 2006 using different grid spacing nested into one another and both parameterised and explicit convection; for further details see Birch et al., 2014; Pearson et al., 2014), and settings in many of the model physics sections, notably the representation of convection, were adopted from there. The SWAMMA simulations are longer than those in Cascade, running from initialisation from 1 May to 30 September 2011 (153 days): this spans an entire monsoon season, allowing for investigation of the development of the West African Monsoon (WAM) in an unprecedented way.

Another important improvement on the Cascade simulations is the inclusion of prognostic interactive dust in the SWAMMA simulations. This allows for the investigation of the dust-raising and transportation characteristics of the model under varying resolutions and convection options, as well as assessing the radiative impact that dust has on the WAM system. The dust scheme used is that within the Coupled Large-scale Aerosol Simulator for Studies in Climate (CLASSIC; Johnson et al., 2011) scheme, in which dust particles are assumed to be spherical and transported in the at- 

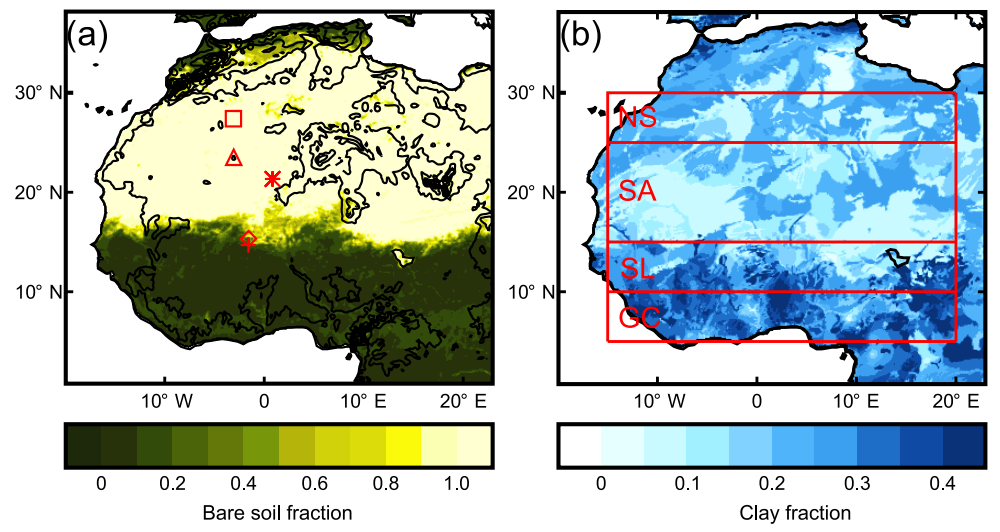

Figure 1. Maps of (a) bare-soil fraction for $12 \mathrm{~km}$ models (filled contours) with orographic height (open contours from $0.2 \mathrm{with} 0.4 \mathrm{~km}$ interval). Locations of Fennec and AMMA stations marked in red: square F138 $\left(27.4^{\circ} \mathrm{N}, 3.0^{\circ} \mathrm{W}\right)$, triangle F134 $\left(23.5^{\circ} \mathrm{N}, 3.0^{\circ} \mathrm{W}\right)$, asterisk Bordj Badji Mokhtar $\left(21.3^{\circ} \mathrm{N}, 0.9^{\circ} \mathrm{E}\right)$, diamond Agoufou $\left(15.3^{\circ} \mathrm{N}, 1.5^{\circ} \mathrm{W}\right)$ and cross Kobou $\left(14.7^{\circ} \mathrm{N}, 1.5^{\circ} \mathrm{W}\right)$ and $(\mathbf{b})$ clay fraction from Harmonised World Soil Database (HWSD) used to define surface soil texture in the models. Red boxes highlight regions referenced in Fig. 3 (northern Sahara (NS, 25-30 N), the Sahara $\left(\mathrm{SA}, 15-25^{\circ} \mathrm{N}\right)$, the Sahel $\left(\mathrm{SL}, 10-15^{\circ} \mathrm{N}\right)$ and the Guinea coast $\left(\mathrm{GC}, 5-10^{\circ} \mathrm{N}\right)$, all with longitudes $\left.15^{\circ} \mathrm{W}-20^{\circ} \mathrm{E}\right)$.

mosphere as six independent tracers undergoing dry deposition through turbulent mixing and gravitational settling as well as wet deposition through washout from precipitation. Dust emissions are calculated during each model time step using prognostic model fields. The dust emission scheme utilises the widely used algorithm of Marticorena and Bergametti (1995) to calculate horizontal flux in each of nine bins with boundaries at $0.0316,0.1,0.316,1.0,3.16,10.0,31.6$, $100 ., 316$ and $1000 \mu \mathrm{m}$ radius (the largest three of the size modes are only active in saltation processes). Each of the six dust size bins is treated independently by the radiation scheme with spectral properties being calculated from Mie theory. The horizontal dust flux for dust particles in each size bin is calculated as a function of the cube of the surface friction velocity $\left(U^{*}\right)$, the bare-soil fraction in the grid box (shown in Fig. 1), the mass fraction of soil particles available at the surface, and a threshold surface friction velocity $\left(U_{t}^{*}\right)$ below which dust is not mobilised. Assuming that the lowest model level (for wind speed) is with the turbulent boundary near the surface, then the calculation of $U^{*}$ should be insensitive to different vertical grid spacings. This seems to be the case in the SWAMMA simulations with there being no clear relationship between different grid spacings across the suite of simulations and the model diagnostic $U^{*}$ values. The threshold value $\left(U_{t}^{*}\right)$ is a function of soil moisture in the top layer $(10 \mathrm{~cm}$ thick in the model) and the clay fraction in the grid box, such that emissions are inhibited for wet soils (further details in Woodward 2011; Ackerley et al., 2012). Dust emission models may be tuned by adjusting coefficients by which $U^{*}$ and the top-level soil moisture are multiplied with a global tuning factor. Here the values used are 1.6, 0.5 and 2.5 respectively, and values were not adjusted for different model grid spacings in order to make a fair comparison between the model run at different resolutions. The Harmo- nized World Soil Database (FAO, 2012) is used to determine soil texture and thus the fractions of clay, silt and sand available in each surface grid box for the dust emission scheme. Dust fields are initialised from zero and drop to zero on the lateral boundaries (so that no dust enters the domain at the boundaries). Surface infra-red emissivity is changed from the JULES default value over bare soil (0.97) to 0.9 for these experiments, as this is more realistic over the Sahara (Ogawa and Schmugge, 2004). As described above there is no explicit use of preferential dust sources; however, where soil characteristics and surface roughness are favourable the threshold friction velocity over bare soil $\left(U_{t}^{*}\right)$ can be reduced, allowing for favourable emission conditions in particular regions.

Within the framework described above, eight simulations are conducted which comprise the SWAMMA model suite. The main variable factors between the simulations are grid spacing, representation of convection and radiatively interactive mineral dust (see Table 1). In simulations with parameterised convection the convective scheme in the UM is switched on (Stratton et al., 2009). This scheme is based on a convective available potential energy (CAPE) closure method, where high CAPE values are identified and tendencies are determined to reduce this over a given timescale. In the simulations with explicit convection the convective parameterisation has effectively been switched off by increasing the CAPE closure timescale to a point at which CAPE depletion by the parameterisation is insignificant. These models employ a Smagorinsky-style subgrid-scale mixing in all three dimensions (3DS in Table 1) with mixing length constants chosen as those found optimal for the 12 and $4 \mathrm{~km}$ models in Cascade (0.05 and 0.1 respectively). In the simulations with radiatively active dust, mineral dust emitted from the surface within the simulations influences the radiation budget via its direct radiative effect (scattering and absorb- 
Table 1. Summary of model simulations run in SWAMMA.

\begin{tabular}{lrllrrrr}
\hline $\begin{array}{l}\text { Experiment } \\
\text { name }\end{array}$ & $\begin{array}{r}\text { Horizontal grid } \\
\text { length }(\mathrm{km})\end{array}$ & $\begin{array}{l}\text { Convection } \\
\text { type }\end{array}$ & $\begin{array}{l}\text { Dust radiation } \\
\text { effect }\end{array}$ & $\begin{array}{r}\text { Number of } \\
\text { levels }\end{array}$ & $\begin{array}{r}\text { Top } \\
(\mathrm{km})\end{array}$ & $\begin{array}{r}\text { Time step } \\
(\mathrm{min})\end{array}$ & $\begin{array}{r}\text { Subgrid turbulence } \\
\text { mixed length constant }\end{array}$ \\
\hline $4 \mathrm{E}+\mathrm{Fx}$ & 4 & Explicit (3DS) & $\mathrm{Y}$ & 70 & 40 & 1.67 & 0.1 \\
$4 \mathrm{E}$ & 4 & Explicit (3DS) & $\mathrm{N}$ & 70 & 40 & 1.67 & 0.1 \\
& & & & 70 & 80 & 2.5 & 0.05 \\
$12 \mathrm{E}+\mathrm{Fx}$ & 12 & Explicit (3DS) & $\mathrm{Y}$ & 70 & 80 & 2.5 & 0.05 \\
$12 \mathrm{E}$ & 12 & Explicit (3DS) & $\mathrm{N}$ & 70 & 80 & 2.5 & $\mathrm{n} / \mathrm{a}$ \\
$12 \mathrm{P}+\mathrm{Fx}$ & 12 & Parameterised & $\mathrm{Y}$ & 70 & 80 & 2.5 & $\mathrm{n} / \mathrm{a}$ \\
$12 \mathrm{P}$ & 12 & Parameterised & $\mathrm{N}$ & & & & $\mathrm{n} / \mathrm{a}$ \\
& & & & 70 & 80 & 2.5 & $\mathrm{n} / \mathrm{a}$ \\
$40 \mathrm{P}+\mathrm{Fx}$ & 40 & Parameterised & $\mathrm{Y}$ & 70 & 80 & 2.5 & \\
$40 \mathrm{P}$ & 40 & Parameterised & $\mathrm{N}$ & & & & \\
\hline
\end{tabular}

ing solar and thermal radiation); cloud microphysical effects are not included. While dust is present in the radiatively inactive simulations it does not influence the radiation budget or the evolution of the model meteorology. Comparing simulations with different convection types but without dust effects (e.g. 12P and 12E in Table 1) highlights the impact of resolved convection on dust generation without complications of feedbacks through dust-radiation interactions. We focus on the latter in this paper, although here we note that effects of interactive dust on both dust uplift itself and thermodynamics are far smaller than those that change the convection (not shown).

\subsection{Observational data}

\subsubsection{MODIS AOD (TERRA)}

We use AOD at $550 \mathrm{~nm}$ from the Moderate Resolution Imaging Spectroradiometer (MODIS) Collection 6 merged scientific data set (SDS) available from the NASA Giovanni online data system (Acker and Leptoukh, 2007). This data set combines the new enhanced deep blue (DB) SDS, now available over all cloud-free and snow-free land surfaces (and therefore including dark vegetated surfaces), and dark target (DT) land and ocean SDS (Sayer et al., 2014). This produces a more spatially complete SDS over both land and ocean. The DB algorithm has provided a much improved technique for the retrieval of AOD values over bright surfaces compared to DT. Maps and libraries of surface reflectance in the blue part of the spectrum are used to produce AOD values that compare well with the AErosol RObotic NEtwork (AERONET). The estimated error is $0.05+20 \%$, with $79 \%$ of the best AOD data falling within this range (Hsu et al., 2013). The merged MODIS AOD product uses DB data over surfaces where the Normalized Difference Vegetation Index (NDVI) $\leq 0.2$ and DT data where NDVI $\geq 0.3$. For intermediate NDVI regions, the algorithm with the higher-quality assurance flag is used. Sayer et al. (2014) provide a detailed analysis of these products and note that DB performance is poorer over dusty regions compared to the global average, with an overall tendency to underestimate AOD in dusty environments. Additionally they find that, in the Sahel, contributions to AOD from different aerosol types are likely to contribute to frequently different AODs retrieved by the two algorithms, though DB performs better than DT in this region. Therefore when the merged SDS draws data from the DT SDS, the quality is reduced in the Sahel. Here we present the merged MODIS SDS since it provides a more continuous data set for comparison over the SWAMMA domain than simply the DB SDS. We show data from the Terra satellite with a 10:30 LST overpass, L3 monthly mean data with a spatial resolution of $1^{\circ}$. Where appropriate, simulations are similarly subsampled to the approximate MODIS TERRA overpass time to reduce erroneous comparisons of different parts of the diurnal cycle. This gives a good spatial comparison of AOD on the monthly timescales that are studied in this work.

It is also noteworthy that most of the available in situ observations (AERONET and the AMMA dust transect $\mathrm{PM}_{10}$ ) are on the fringes of the Sahara, and therefore the values are dominated by the transport of dust rather than locally emitted dust. AERONET observations were investigated for model comparisons (not shown). However, due to limitations of spatial and temporal coverage across the simulation region and period the merged MODIS AOD product was selected instead. We also note that analysis of $\mathrm{PM}_{10}$ from the AMMA dust transect (Marticorena et al., 2010) may provide further insights into the role of the bias in land surface characteristics noted for the Sahel, but this is beyond the scope of this paper. The focus of this work requires the analysis of the spatial distribution of dust in the dust uplift hotspot of the Sahara across all simulated months for comparison with the SWAMMA simulations. For this reason MODIS AOD values were favoured over other widely used observational products.

We note that there are anomalously high MODIS-merged AODs present in Fig. 2 in June around $0-10^{\circ} \mathrm{N}, 15-30^{\circ} \mathrm{E}$ (bottom right corner - southern Sudan and Central African Republic) and to some extent in this region in July as well. 

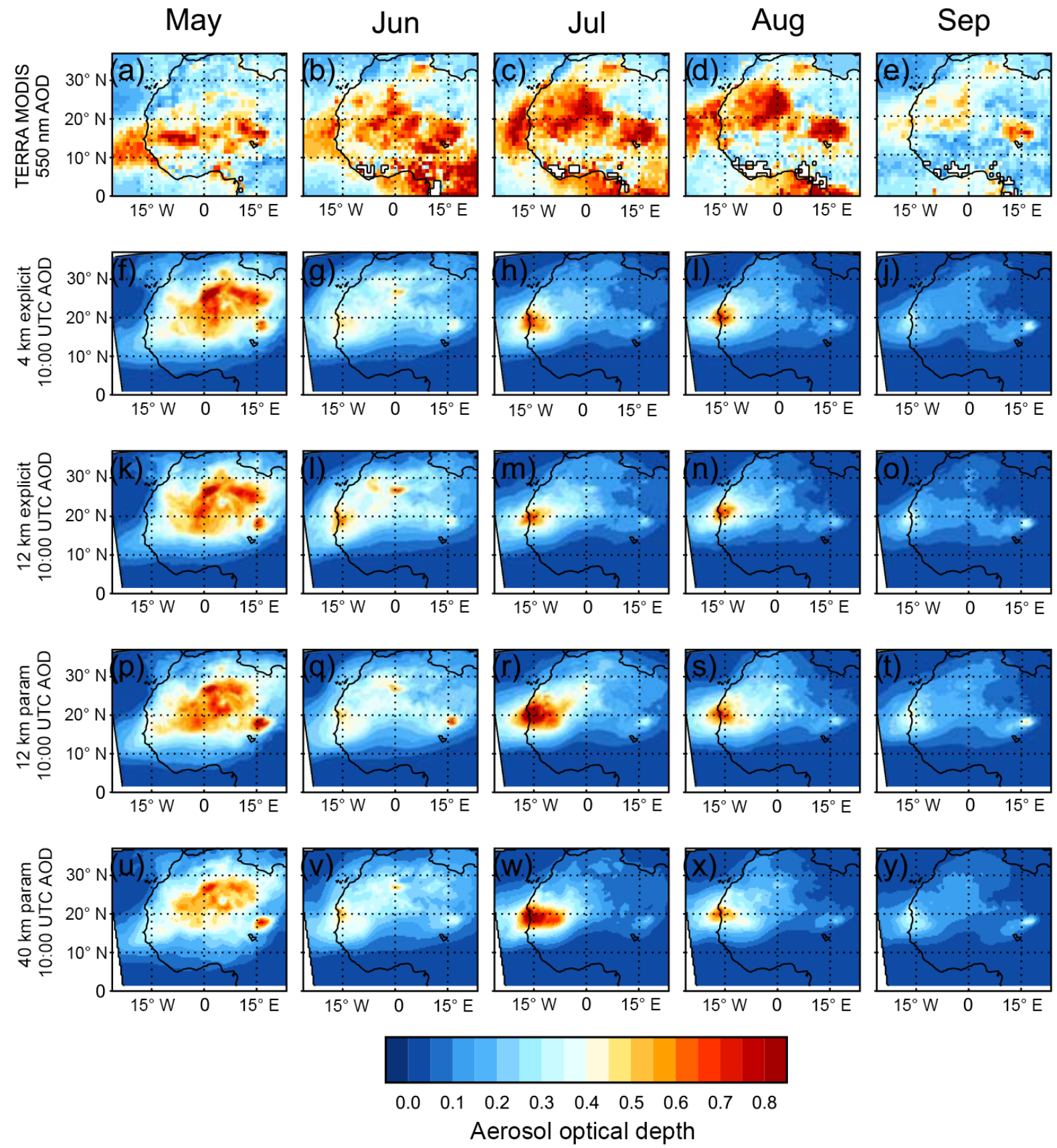

Figure 2. Monthly mean (May-September, left-right) aerosol optical depths (AODs) at 10:00 UTC from (a-e), MODIS Terra satellite (combined deep blue and land-ocean data sets), (f-j) $4 \mathrm{~km}$ simulation with explicit convection (4E), (k-o) $12 \mathrm{~km}$ simulation with explicit convection (12E), (p-t) $12 \mathrm{~km}$ simulation with parameterised convection (12P) and (u-y) $40 \mathrm{~km}$ simulation with parameterised convection (40P). Simulations have been subsampled temporally to the TERRA MODIS overpass time to allow for a reduction in differences introduced through the diurnal cycle.

These high AODs are not present in the DB SDS (not shown) as they originate from the DT SDS (not shown). These anomalies have been identified as a result of an AOD dependence on solar angle investigated in detail in Wu et al. (2016). We therefore consider this region of high AOD to be an artefact of the DT contribution to the merged SDS, which in this particular case is likely to be less reliable due to the reasons explained above. 


\subsubsection{SEVIRI RGB dust imagery}

False colour red-green-blue (RGB) dust imagery from the EUMETSAT Spinning Enhanced Visual and Infrared Imager (SEVIRI) is used to give a qualitative understanding of the uplift of dust associated with a large cold pool. The $15 \mathrm{~min}$ time resolution and very wide field of view mean SEVIRI data are extremely useful for visual tracking and interpreting the development of individual systems. To highlight regions of raised dust the product compares brightness temperature and brightness temperature differences between three of SEVIRI's infrared channels (channels 7, 9 and 10 which correspond to 8.7, 10.8 and $12 \mu \mathrm{m}$ wavelengths respectively). While the magenta colour associated with raised dust can be indicative of important dust uplift mechanisms, there are several limitations to its use. These include biases caused by the height of the dust layer, the lower tropospheric lapse rate and masking of lifted dust by high column water vapour (Brindley et al., 2012).

\subsubsection{SEVIRI AERUS-GEO AOD}

The AERUS-GEO (Aerosol and surface albEdo Retrieval Using a directional Splitting method-application to GEOstationary data) AOD is a daily daytime-only mean measure of AOD (Carrer et al., 2014). The approach used to produce the AERUS-GEO product is detailed in Carrer et al. (2010) and Carrer et al. (2014). The relatively invariant nature of the land surface albedo on a daily timescale compared to the atmosphere is used along with the high temporal resolution of SEVIRI retrievals (full disc scan every $15 \mathrm{~min}$ ) to distinguish the $0.63 \mu \mathrm{m}$ signal from aerosols from that of the surface. The AERUS-GEO product has good accuracy when compared with other satellite-derived AOD products (typically less than $20 \%$ deviation from AERONET) and has much better spatial and temporal coverage than products that utilise data from polar-orbiting satellites.

\subsection{Surface wind observations}

Wind speed observations from several in situ observation platforms are compared with simulated wind speeds. Data from five stations are used, these are Fennec automatic weather stations (AWSs) $134\left(23.5^{\circ} \mathrm{N}, 3.0^{\circ} \mathrm{W}\right)$ and $138\left(27.4^{\circ} \mathrm{N}, 3.0^{\circ} \mathrm{W}\right)$, the Fennec flux tower deployed at Bordj Badji Mokhtar (BBM; 28.3 $\left.{ }^{\circ} \mathrm{N}, 0.9^{\circ} \mathrm{E}\right)$ and African Monsoon Multidisciplinary Analysis (AMMA) "Couplage de l'Atmosphère Tropicale et du Cycle Hydrologique" $(\mathrm{CATCH}) \mathrm{AWSs}$ at Agoufou $\left(15.3^{\circ} \mathrm{N}, 1.5^{\circ} \mathrm{W}\right)$ and Kobou $\left(14.7^{\circ} \mathrm{N}, 1.5^{\circ} \mathrm{W}\right)$. Different dust uplift mechanisms occur at different times of the day. The advantage of these observations compared to routine synoptic observations is their high temporal resolution (which allows for resolution of the diurnal cycle) as well as the geographical spread of stations across the Sahel and Sahara, which are generally very poorly observed. To compare between simulations and observations taken at different heights, all winds are adjusted to $2 \mathrm{~m}$ height using the wind profile power law $u=u_{\mathrm{r}}\left(z / z_{\mathrm{r}}\right)^{\alpha}$, where $u_{\mathrm{r}}$ is wind speed reference height $\left(z_{\mathrm{r}}\right), z$ is the height to be adjusted, and $\alpha$ is a stability coefficient (nominally 0.143 ; Touma, 1977; Roberts et al., 2017).

\subsubsection{Fennec AWS}

The Fennec project aimed to improve the understanding of Saharan meteorology with a particular focus on the processes associated with dust uplift and transport. Eight Fennec AWSs were distributed across the Sahara in Algeria and Mauritania in late May 2011 and continued to operate into 2013. The structure of the AWSs and the observations that were made are detailed in Hobby et al. (2013). Unfortunately during 2011 a number of the AWSs experienced problems associated with overheating, leaving only F-134 and F-138 with good data coverage over the SWAMMA simulation period (Roberts et al., 2017). Wind observations were transmitted via satellite and comprised 3 min $20 \mathrm{~s}$ mean wind speed values from the cup anemometers at $2 \mathrm{~m}$ a.g.l.

\subsubsection{Fennec BBM supersite}

Also deployed as part of the Fennec campaign was a more comprehensive suite of instruments at two supersites at BBM (Algeria) and Zourate (Mauritania). The wind speed observations that are used in this study are from the flux tower deployed at BBM (Zourate data do not extend sufficiently over the simulated period). The supersite has no wind speed data for May but has data for 25 days in June, 31 days in July, 31 days in August and 3 days in September. This allows for comparison between simulations and observations for 3 of the 5 simulated months within the West African summertime dust hotspot (Englestaedter and Washington, 2007; Knippertz and Todd, 2010). Marsham et al. (2013) detail the instrumentation deployed at the BBM supersite. Wind measurements used in this study are from a sonic anemometer positioned at $10 \mathrm{~m}$ a.g.l. The sampling frequency is $20 \mathrm{~Hz}$ but $1 \mathrm{~h}$ means have been calculated for comparison with simulations and other observed winds.

\subsubsection{AMMA-CATCH stations}

The AMMA field campaign (Lebel et al., 2011), primarily conducted in 2006, had the aim of improving the understanding of the WAM system. Observations over a large area and over a large timescale were conducted, including the deployment of AWSs. Of the many AWSs deployed, two of those have been used in this study and were part of the AMMA CATCH programme, which specifically had the objective of looking at interannual variability of the WAM system. These stations (Agoufou and Kobou), were deployed ready for the main AMMA-observing period in 2006 and were still operational in 2011. This allows for unprecedented comparison 
between simulations and observations in the Sahel and Sahara, with observations that are temporally coincident.

\subsection{Storm tracking}

To investigate the nature of mesoscale convective systems seen in observations and those generated in convectionpermitting simulations a storm-tracking approach has been adopted. The algorithm used is based on that of Stein et al. (2014) and has been modified for use on both simulations and observations (Crook et al., 2018). The algorithm can be applied to either rainfall or brightness temperatures to track convective systems over West Africa. Storm clusters are identified through the use of a threshold and by grouping contiguous cells. These are then followed in time using a fractional overlap method ( 0.6 overlap threshold) to track storm cells, allowing for both cell splitting and merging. If a storm has no overlapping cells from the previous time step, then it is a new initiation. When a storm has no overlapping cells in the next time step, it is a dissipation. For splits the cell with the greatest overlap retains its storm ID, while other cells are said to have split and are given new storm IDs (parent IDs are recorded). Similarly, for merging, the cell from the previous time step with the greatest overlap with the resultant cluster maintains its ID and any other cells with smaller overlaps are said to have merged and take the ID of the cell with the largest overlap. For this study it was decided that a brightness temperature approach, using a threshold of $-40^{\circ} \mathrm{C}$ would be best suited. This is due to the use of hourly data for tracking, where clouds give a greater overlap and therefore a chance of tracking between time steps. This is also because we are interested in systems for which rain does and does not reach the surface, since both situations can produce haboobs, making rainfall tracking less reliable. Therefore, for this study, hourly brightness temperatures calculated from both simulated and observed (SEVIRI channel 9, $10.8 \mu \mathrm{m}$ ) outgoing long-wave radiation has been used to track systems, giving information about storm triggering, locations, size and storm lifetime.

\section{Results}

\subsection{Impact of resolving convection on dust AOD and dust emission}

Comparisons of dust AODs with observations are frequently used to verify (and in many cases, tune) dust models (Huneeus et al., 2011, 2016). This is because AOD observations from satellites are now available at high temporal and spatial resolutions, unlike observations of dust emissions and concentrations. However, within a modelling framework AOD is very much an end product, requiring not only accurate representations of all the physical processes involved in dust emission, transport and deposition to achieve realistic dust loadings but also accurate representations of particle size distribution and spectral optical properties. For example, in the SWAMMA experiments, although extinction per unit mass is greatest for particle size division $2(0.1-0.3 \mu \mathrm{m}$ mean radius), dust mass is maximum in division $4(1-3 \mu \mathrm{m}$ mean radius), and total extinction for dust is dominated by particles in size division $3(0.3-1 \mu \mathrm{m}$ mean radius). On the other hand, models with very similar AODs can have very different dust emissions due to compensating differences in deposition, transport or particle size distribution (Kinne et al., 2003; Ocko and Ginoux 2016; Evan et al., 2014).

The dust loadings in the SWAMMA experiments (5-6 Tg May to September seasonal mean for the whole domain) are at the low end of, but not outside, the range reported by other modelling studies (this of course could be resolved by tuning total emissions, but would not affect the systematic model biases we investigate here); Huneeus et al. (2011) reviewed 15 global models within the AeroCom project and found global loadings ranged between 7 and $30 \mathrm{Tg}$, of which $\sim 70 \%$ has been estimated to be attributable to the Sahara (Luo et al., 2003). All versions of the model here are initialised with zero dust and found to be spun-up within 5-10 days; for ease of analysis and consistency with presentation, monthly means for May are presented here for the whole month with no special treatment of the spin-up period (it should be noted that even including spin-up May results in dust and AOD values in excess of any other simulated month).

Figure 2 displays the monthly mean (May-September) AODs at $550 \mathrm{~nm}$ from the MODIS Terra satellite with the dust AOD from all the SWAMMA models excluding dust radiative effects (4E, 12E, 12P and 40P from Table 1). Here the model AOD at 10:00 UTC has been selected to provide a better time match for the Terra data which overpass the region at approximately 10:30 LST. As Fig. 2 shows monthly mean values of AOD at approximately 10:00 UTC for both simulations and satellite retrievals, we believe that this is a good comparison with which the overall differences in the spatial distribution of dust in both reality and the simulations can be judged. It is clear that the models are very similar across all resolutions and all feature a maximum over the Bodélé depression $\left(\sim 18^{\circ} \mathrm{N}, 19^{\circ} \mathrm{E}\right)$ in all months, in common with the MODIS data. However, apart from in May, the models all have insufficient dust over the central Sahara and a strong maximum over the west coast at $\sim 20^{\circ} \mathrm{N}$, which is not evident in the MODIS data. These are common features of many models (e.g. Fig. 2 of Todd and CavazosGuerra, 2016, Fig. 6 of Ridley et al., 2012) and, as pointed out by Evan et al. (2014) in a multi-model CMIP5 comparison study, may have many contributory factors, including a poor representation of soil texture, moisture and vegetation cover, and deficiencies in model surface winds. The focus of this study is to see if any improvement can be achieved by resolving convection explicitly, since haboobs are known to be a key uplift mechanism in the summertime central Sahara. Figure 3 therefore compares the spatial correlations and biases (at model grid points) for the $12 \mathrm{~km}$ simulations with 
$12 \mathrm{~km}$ simulations vs. MODIS AOD correlation

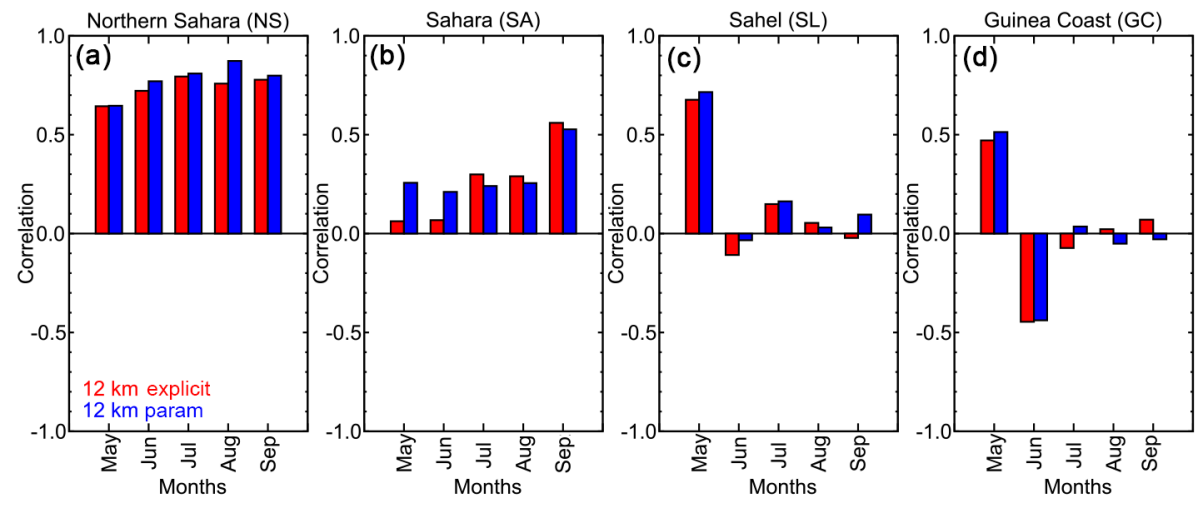

$12 \mathrm{~km}$ simulations vs. MODIS AOD bias

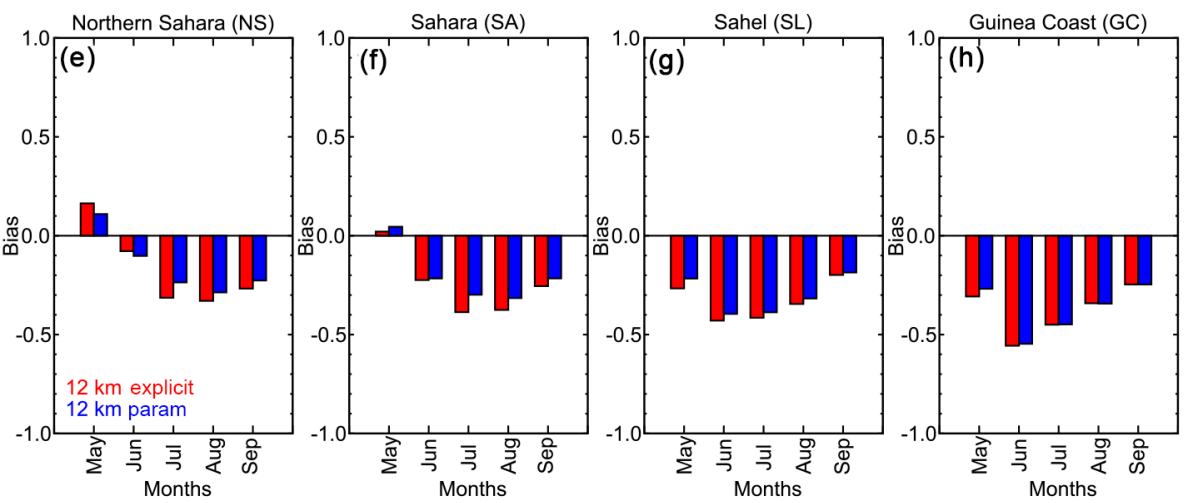

Figure 3. Aerosol optical depth (AOD) correlation coefficients and biases between $12 \mathrm{~km}$ simulations (explicit and parameterised 10:00 UTC) and MODIS AOD retrievals ( 10:00 UTC). (a-d) Monthly mean (May-September) model AOD vs. MODIS AOD correlation coefficients. (e-h) Monthly mean (May-September) model - MODIS AOD biases. Shown are $12 \mathrm{~km}$ explicit convection simulation (12E, red) and 12 km parameterised convection simulation (12P, blue). Correlations and biases calculated from boxes shown and labelled in Fig. 1 (a-e northern Sahara (NS) box, (b) and (f) Sahara (SA) box, (c) and (g) Sahel (SL) box and (d) and (h) Guinea coast (GC) box).

explicit and parameterised convection (12E and $12 \mathrm{P})$ relative to the MODIS AODs, broken down into specific regions as shown by the boxes in Fig. 1b: northern Sahara (NS, $\left.25-30^{\circ} \mathrm{N}\right)$, the Sahara (SA, $\left.15-25^{\circ} \mathrm{N}\right)$, the Sahel (SL, $\left.10-15^{\circ} \mathrm{N}\right)$ and the Guinea coast $\left(\mathrm{GC}, 5-10^{\circ} \mathrm{N}\right)$. As mentioned in Sect. 2.2.1 MODIS AOD retrievals are compared with the nearest corresponding times from simulations to reduce errors from diurnal variations. Overall, where they are significant (>0.5), correlations are positive, except for the Guinea coast region in June where dust loads are lower and, as noted in Sect. 2.2.1, MODIS data are anomalous. Correlations are high $(>0.5)$ for the northern Sahara throughout the season and also in May in the Sahel, and lower at other locations and times, which are when moist convection and haboobs are known to be most active. Differences between the explicit and parameterised versions of the model are small, with the parameterised version generally having slightly better correlations with MODIS except for July-September in the Sahara. Despite the low correlations in the summertime
Sahara, this is the region where we would look to find improvements in dust in the convection-permitting simulations. This is due to the expectation that in this region there are areas with surface characteristics that allow for the deflation of dust, as well as the additional uplift process that is expected to be represented (haboobs). The model AOD biases relative to MODIS data are predominantly negative and have the greatest magnitude to the south of the SWAMMA region, consistent with the model producing too little dust there (although the maximum bias of $\sim-0.55$ in June in the Guinea coastal region is where the MODIS data are anomalous). Exceptions to this are the northern Sahara and Sahara in May, where biases are positive but small, suggesting too little dust in regions and seasons in which moist convection is most active but too much prior to the monsoon onset and close to the Atlantic coast. Where there are differences between explicit and parameterised simulations, the explicit version mostly has larger biases than the parameterised model, although the differences are small. 

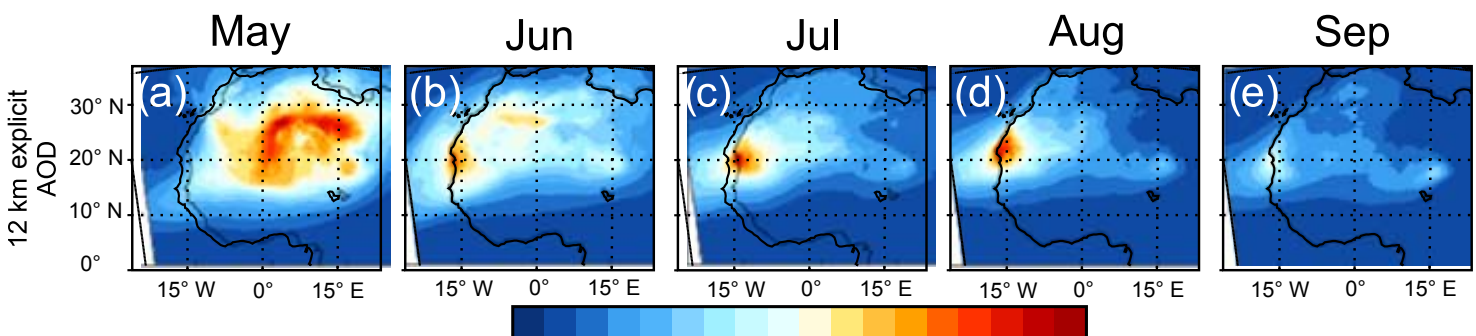

$\begin{array}{lllllllll}0.0 & 0.1 & 0.2 & 0.3 & 0.4 & 0.5 & 0.6 & 0.7 & 0.8\end{array}$

Aerosol optical depth
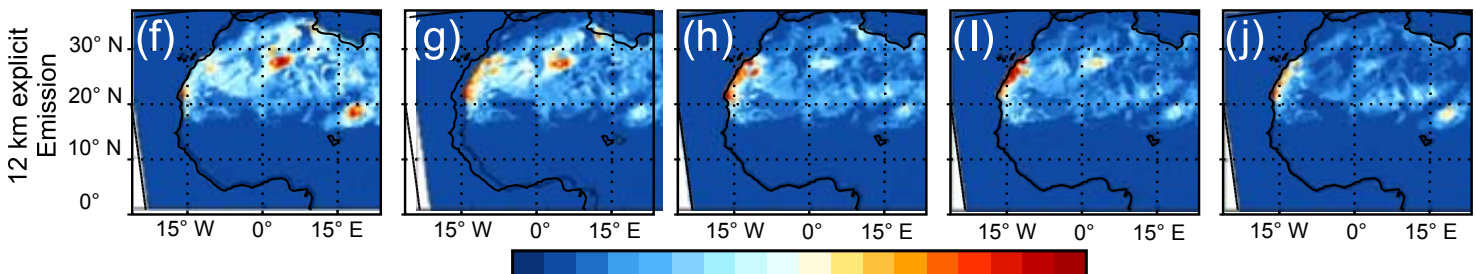

$\begin{array}{lllllllll}0.0 & 0.4 & 0.8 & 1.2 & 1.6 & 2.0 & 2.4 & 2.8 & 3.2\end{array}$

Emission $\left(\mathrm{g} \mathrm{m}^{-2}\right.$ day $\left.^{-1}\right)$
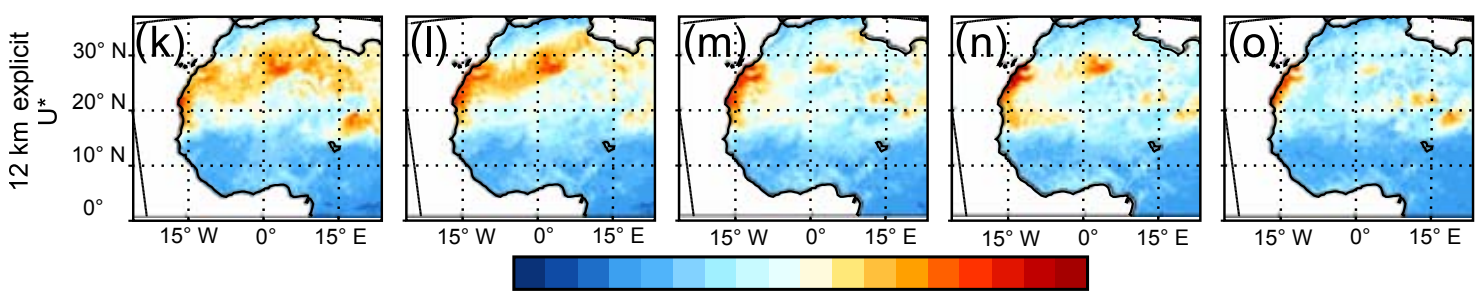

$\begin{array}{lllllllll}0.0 & 5.0 & 10.0 & 15.0 & 20.0 & 25.0 & 30.0 & 35.0 & 40.0\end{array}$ $\mathrm{U}^{*}\left(\mathrm{~cm} \mathrm{~s}^{-1}\right)$
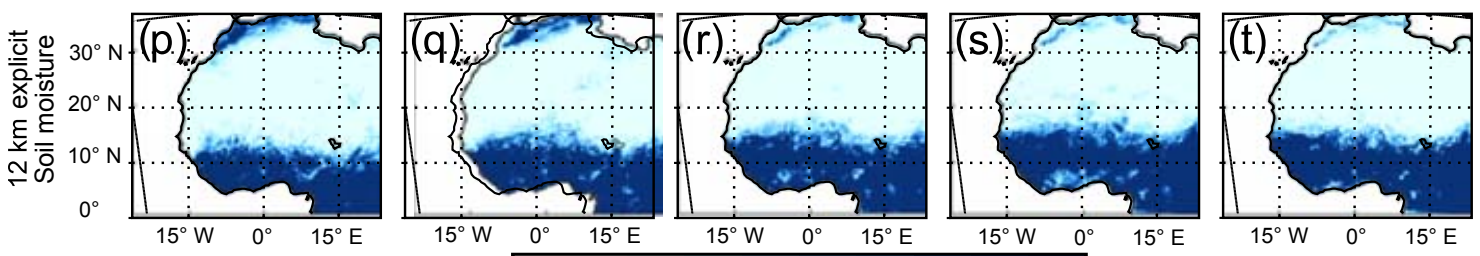

0.0

$\begin{array}{lll}5.0 & 10.0 \quad 15.0 \\ & & \\ & & \end{array}$

20.0

Figure 4. Monthly mean (May-September) maps showing (a-e) aerosol optical depth (AOD), (f-j) dust emission, (k-o) friction velocity over bare soil $\left(U^{*}\right)$ and $(\mathbf{p}-\mathbf{t})$ soil moisture from the $12 \mathrm{~km}$ simulation with explicit convection (12E).

All the SWAMMA models lack the AOD maximum evident in the MODIS data from June to August in the central Sahara. We therefore examine factors affecting the dust emission to see why this might be. Figure 4 shows the monthly mean (May-September) dust AODs (for all hours), with the corresponding dust emissions, surface friction velocity over bare soil $\left(U^{*}\right)$ and soil moisture in the top $10 \mathrm{~cm}$ soil layer for the $12 \mathrm{~km}$ explicit convection model (12E). Reference to the clay fractions in Fig. 1 is also helpful, as it is a factor in the vertical dust flux equation. Areas with high clay fraction (up to a maximum value of 0.2 ) have the potential to pro- duce the most dust in dry conditions. However it is also the case that high clay soils are more sensitive to soil moisture, with higher soil moisture values impeding emission. South of approximately $15^{\circ} \mathrm{N}$, emission of dust is negligible due to the very small bare-soil fractions (see Fig. 1) and higher soil moisture values (Fig. 4); although the JULES surface exchange scheme includes a seasonal climatology of fractional leaf area index (LAI), the fraction of each land type, including bare soil, is fixed. It is known that there is a strong seasonal cycle in vegetation over the Sahel (Mougin et al., 2009) with summertime dust emission from haboobs during 

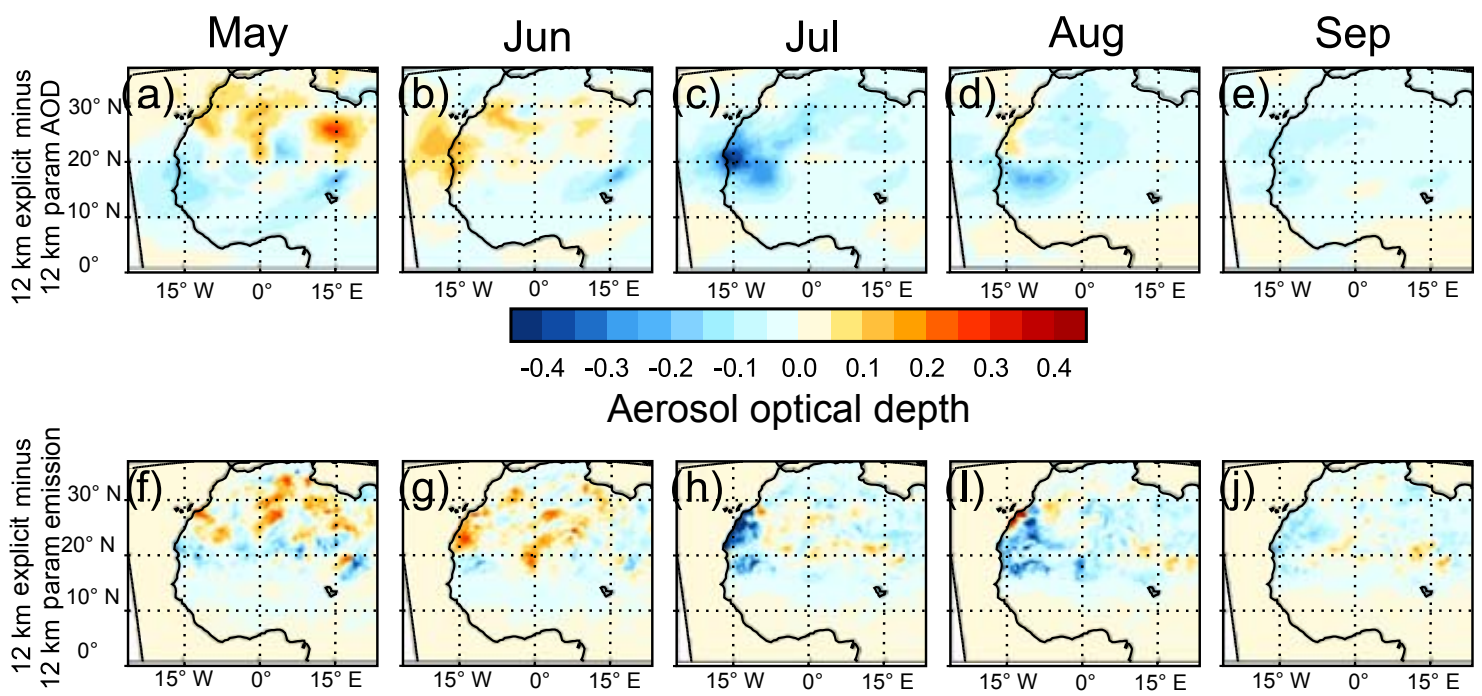

Aerosol optical depth
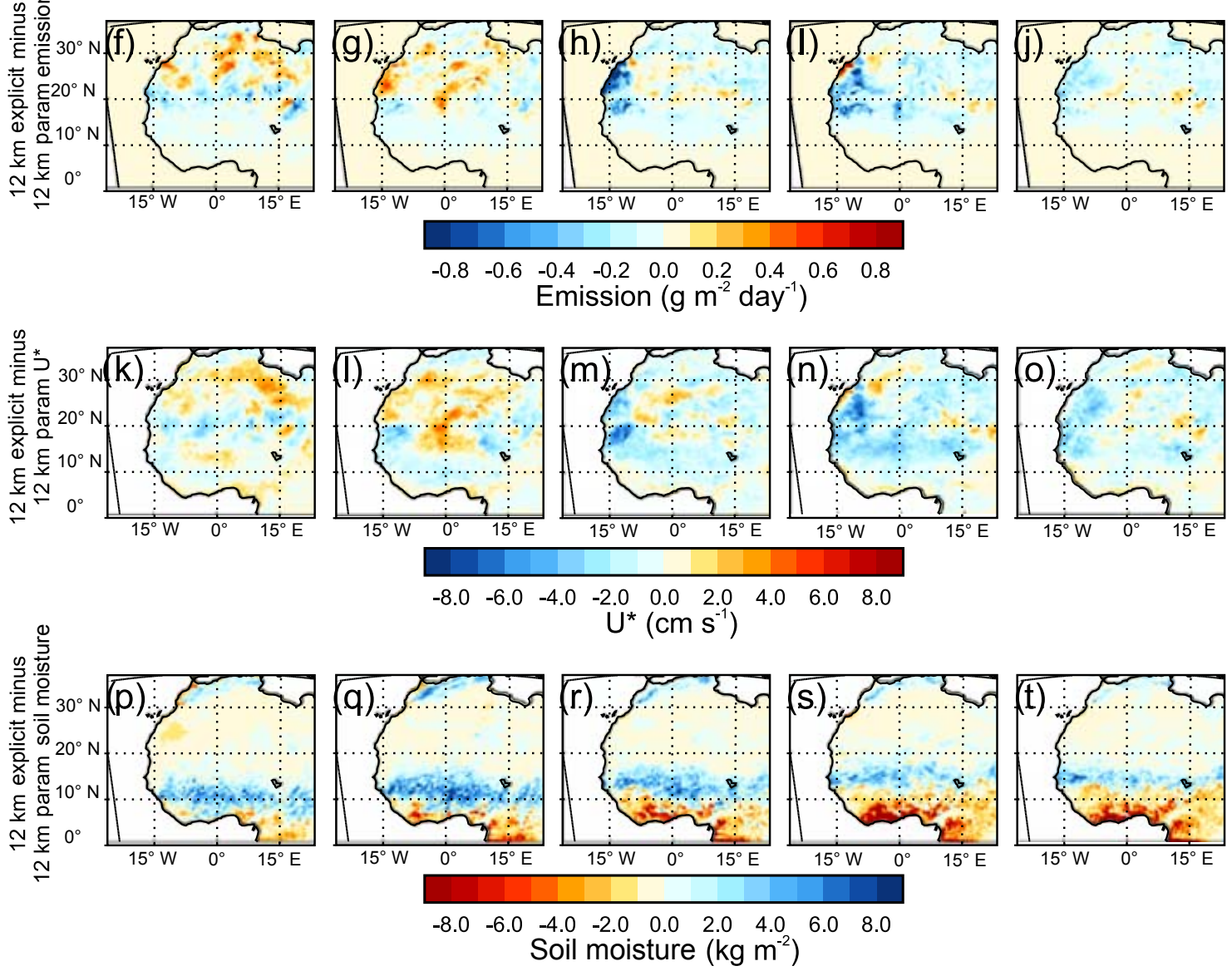

Figure 5. Monthly mean (May-September) difference maps showing (a-e) aerosol optical depth (AOD), (f-j) dust emission, (k-o) friction velocity over bare soil $\left(U^{*}\right)$ and $(\mathbf{p}-\mathbf{t})$ soil moisture between $12 \mathrm{~km}$ simulation with explicit convection and $12 \mathrm{~km}$ simulation with parameterised convection (12E-12P).

the early monsoon season (June-August; Klose et al., 2010; Knippertz and Todd, 2012), and even cold pools from congestus clouds can lead to visible dust uplift in June (Marsham et al., 2009). This fixed bare-soil fraction therefore means that seasonal dust emission from the Sahel cannot be realistically represented in this configuration of the UM. Figure 4 also shows that, in the model, emissions are strong over the Bodélé, the west coast and central Algeria, where the highest $U^{*}$ values coincide with regions of high clay fraction and low soil moisture. To see the impact of the choice of convection scheme, Fig. 5 shows the differences between the $12 \mathrm{~km}$ explicit and parameterised models for the same variables. There is a clear mid-season switch in the AOD, emissions and $U^{*} 12 \mathrm{E}-12 \mathrm{P}$ differences such that they are generally (over the whole SWAMMA area) much more negative in July-September than in May-June. Differences in soil moisture have relatively little impact on the dust emissions, because they are mainly to the south of the region, where the bare-soil fraction is small. However, it should be noted that the soil moisture available to be input to the emission scheme 
is the top $10 \mathrm{~cm}$ mean soil moisture; this is likely to have a buffering effect on emissions, as in reality the skin soil moisture controls dust emission. This has a much faster timescale for drying and reaching a level appropriate for mineral dust deflation: Gillette et al. (2001) reports sediment from a dry lake in California being raised 10-30 min after rainfall, and Bergametti et al. (2016) reports Sahelian surfaces taking less than $12 \mathrm{~h}$ to fully recover their dry-sand transport potential. Some areas of increased $U^{*}$ and dust emissions are evident for the $12 \mathrm{E}$ model in the central Sahara $\left(\sim 20^{\circ} \mathrm{N}, 0^{\circ} \mathrm{E}\right)$ in June, and to a lesser extent in July, but these do not produce any overall decrease in the MODIS bias of the model for the SA region in Fig. 3 due to compensating increases elsewhere.

Figure 6 summarises the seasonal trends of AOD and in factors affecting the dust AOD in the 12E and 12P models for the northern Sahara (NS), Sahara (SA) and Sahel (SL) regions. We see that for both simulations the AODs (monthly mean values of all available times) are poorly simulated with their highest values in May, whereas MODIS AOD increases from May to a maximum in July (for NS and $\mathrm{SA}$ ) and June (for SL). The trend in AOD shown by MODIS retrievals is consistent with the summertime northwards advance of the monsoon, rainfall and haboobs (Marsham et al., 2008). MODIS AOD data from 2006-2008 in Fig. 2 of Ridley et al., 2012 indicate that this pattern is robust and not unique to 2011, indicating that simulations are missing a key dust-generating mechanism providing a maximum in JuneJuly. Additionally we see that the explicit convection version generally performs worse than the parameterised version in this respect. Analysing the contributory factors, the trend in model AOD follows the trend in dust load, as expected (note that loads plotted are regional totals scaled by a factor of 5 for NS and SA, and 10 for SL). The dust loads generally follow the trend in dust emissions, except for May-June in the Sahel where the dust load is boosted by advection from the Sahara. Dust emission trends are strongly driven by the friction velocity $\left(U^{*}\right)$ in NS and SA throughout the season, where soil moisture values are too low to have much influence (except for SA in August where the monsoon rains encroach on the region) and any trend in modelled soil moisture cannot explain the decrease in modelled dust from May to September. For the Sahel the pattern is different, but with lower $U^{*}$ and much higher soil moisture values combining to drastically reduce emissions and dust loads as the monsoon season evolves. In the Sahara and Sahel friction velocity values are generally lower, and soil moisture values higher in the convection-permitting than the parameterised model, leading to lower dust emissions, loadings and AODs (since the monsoon is further north in the explicit run, not shown but consistent with Marsham et al., 2013 and Birch et al., 2014). For the northern Sahara the explicit version has lower soil moisture and higher $U^{*}$ than the parameterised in May-June, leading to higher dust AODs which exceed the MODIS values; however, this is not sustained over the rest of the season and AOD biases are negative for July-September.
The explicit treatment of convection is known (from Cascade; Marsham et al., 2011 and Heinold et al., 2013) to have a strong impact on the representation of haboobs in the UM, but here it does not impact the dust fields significantly. We therefore continue our investigation with an evaluation of the near-surface winds (a strong controlling factor in the emission of dust) in both simulations and observations, to further explain why explicitly permitting haboobs has such a small impact on the modelled dust AODs.

\subsection{Impact of resolving convection on dust-generating winds}

The hypothesis that explicit convection would produce significant differences in the dust field for the SWAMMA simulations has been shown to be incorrect. One potential cause of this is the possibility that the simulated surface winds do not change very much from one simulation to another. Figure 7 shows the distribution of wind speeds adjusted to an observation height of $2 \mathrm{~m}$ using the wind profile power law (Touma, 1977; Roberts et al., 2017) at a number of locations in the Sahel and Sahara for all four simulations (4E, 12E, 12P and 40P) as well as observed winds. There is close agreement in the maximum frequency of occurrence in the simulations at each of the stations, with the observations up to $3 \mathrm{~m} \mathrm{~s}^{-1}$ lower. The largest differences occur in the Sahel. The advantage of showing the distributions on a logarithmic $y$ axis is that the frequency of rare high wind speed events can be examined. While the frequency of such events might be low, the non-linear nature of wind speed to dust uplift (above a threshold) means that they dominate dust uplift (Cowie et al., 2015). The maximum simulated winds (when accounting for height adjustment) are similar to values shown for $10 \mathrm{~m}$ in ALADIN simulations, with parameterised convection in Chaboureau et al. (2016). While the ALADIN simulations with explicit convection show an increased frequency in very strong winds (due to convective cold pools), the SWAMMA simulations show little change in the frequency of very strong winds. It is plausible that models from other centres are also likely to respond differently to the UM. F-134 and BBM in the southern Sahara have both observed high wind speed events that are significantly underrepresented in all of the simulations. This is particularly important as both these stations are located in a region where haboobs are known to be significant and in the seasonal maxima of AOD that can be seen in Fig. 2 (top row) but is absent in all SWAMMA simulations (and CMIP5 simulations). In 3 of the 5 stations the maximum wind values produced in the $4 \mathrm{~km}$ convectionpermitting simulations are lower than that seen in the $12 \mathrm{~km}$ convection-permitting simulation. While this has not been investigated any further here, it highlights a possible scale dependence for the maximum strength of winds that are generated by convective cold pools in convection-permitting models and is possibly linked to scaling of updraught and downdraught column cross sections, although Huang et al. (2018) 

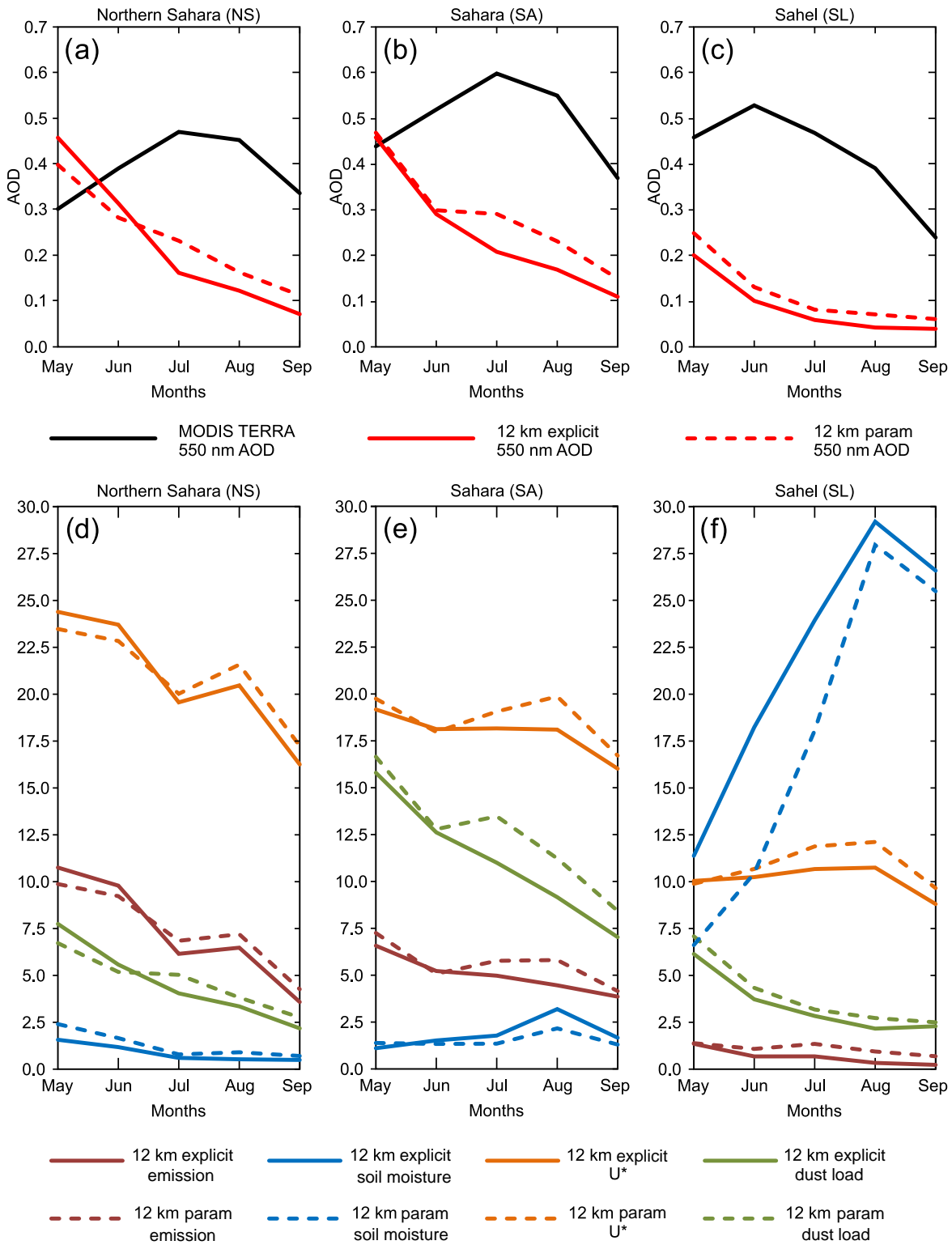

Figure 6. Monthly mean (May-September) aerosol optical depths averaged over (a) the northern Sahara (NS) region, (b) the Sahara region (SA) and (c) the Sahel region (SL). Shown are $12 \mathrm{~km}$ explicit simulation (12E), $12 \mathrm{~km}$ parameterised simulation (12P) and MODIS (Terra). Also shown are (d) NS, (e) SA and (f) SL dust emissions $\left(\mu \mathrm{g} \mathrm{m}^{-2} \mathrm{~s}^{-1}\right)$, total regional dust load (Tg), friction velocity $\left(U^{*}\right.$; $\left.\mathrm{cm} \mathrm{s}^{-1}\right)$ and soil moisture in the top $10 \mathrm{~cm}$ layer $\left(\mathrm{kg} \mathrm{m}^{-2}\right)$. For ease of visibility on the plot, dust loads for NS and SA are scaled by a factor of 5 and for SL dust loads and dust emissions are scaled by a factor of 10 .

suggests that $4 \mathrm{~km}$ subgrid spacing in the cold pool itself is not critical for dust-generating winds.

In order to investigate haboob winds, Fig. $8 \mathrm{a}, \mathrm{b}$ show the anomaly of $10 \mathrm{~m}$ wind speed cubed composited around column maximum rainfall rates greater than $1 \mathrm{~mm} \mathrm{~h}^{-1}$ for the $12 \mathrm{~km}$ simulations with parameterised and explicit convection (over the region $15^{\circ} \mathrm{W}$ to $20^{\circ} \mathrm{E}, 10-30^{\circ} \mathrm{N}$, where it is expected that if a cold pool were to occur it could feasibly raise dust). The anomaly is calculated as the difference from average wind speed cubed values calculated for each sim- ulated month and time of day to reduce the effects of the seasonal and diurnal cycles. The period for the composite average covers the time at which the rain threshold is met and the following $6 \mathrm{~h}$. This highlights the production of convective cold pools in the convection-permitting simulation which have wind speed cubed values in excess of the average for that time of day and season. The peak in the centre of the composite domain in Fig. $8 \mathrm{~b}$ and the absence of a peak in Fig. 8a indicate that cold pools are indeed present in the $12 \mathrm{~km}$ explicit convection simulation and that these fea- 

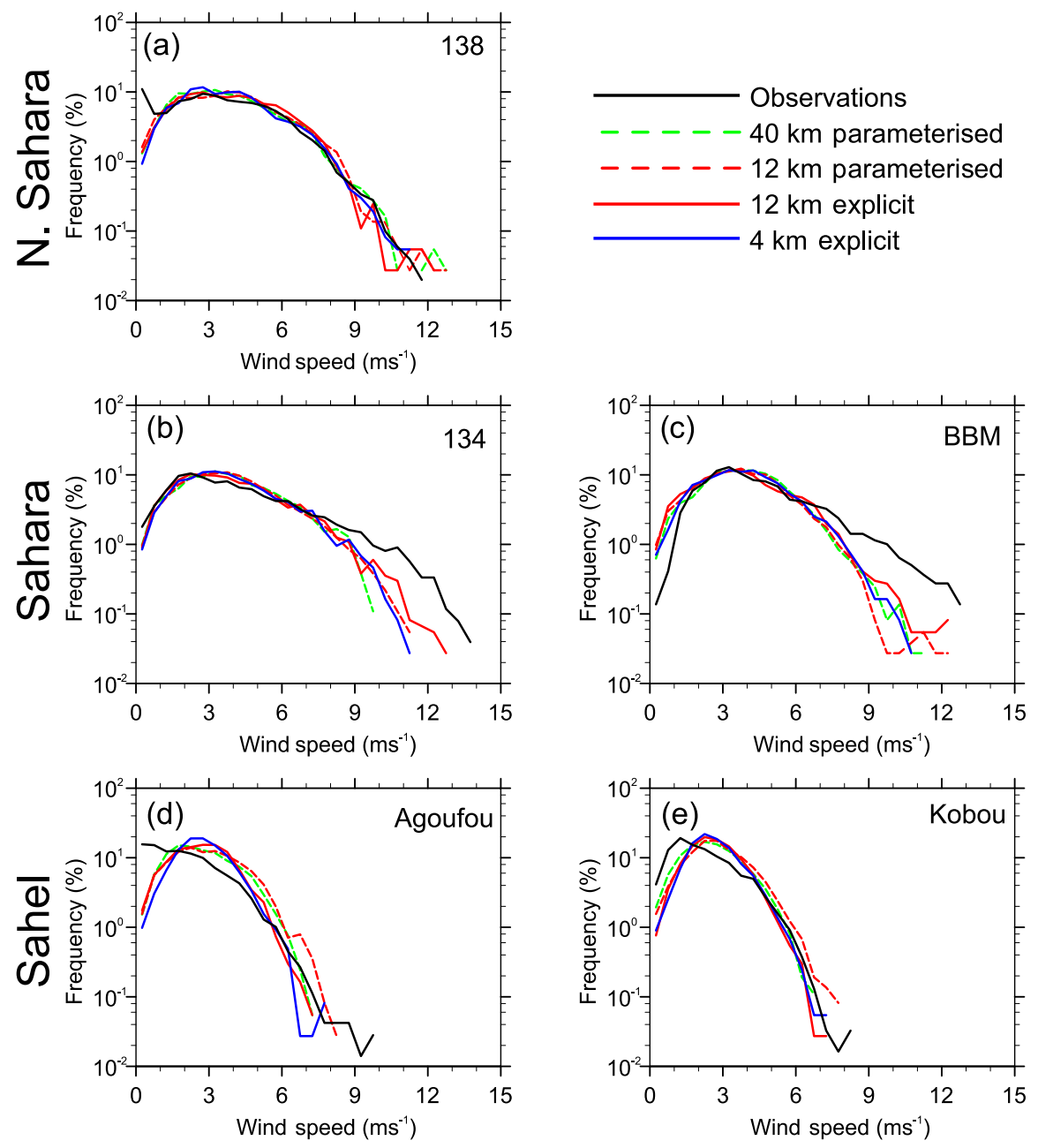

Figure 7. Probability density functions showing the frequency of wind speeds (adjusted to observation height) of different strengths for the observation stations and the closest simulated grid box. Rows indicate the box from Fig. 1 in which the stations are located. Black indicates observations and colours and dashed lines indicate grid spacing and representation of convection of the four simulations.

tures are absent in the parameterised version. Another important feature of the cold-pool anomaly shown in Fig. 8b is the extent of the positive anomaly field. Although this cannot provide a direct measurement of the size of cold pools in the simulation it clearly indicates that they can reach very large sizes (in excess of $300 \mathrm{~km}$ radii). With cold pools of this size it might be expected that there would be a noticeable impact on the uplift of dust and therefore the distribution of AOD. Figure 8c, $d$ are the same type of composite as Fig. $8 \mathrm{a}, \mathrm{b}$ but for the maximum $10 \mathrm{~m}$ wind speed recorded within the rainfall plus the $6 \mathrm{~h}$ window described above. This gives greater information about the actual strength of the winds generated by the presence of convectively generated cold pools. The maximum wind speed composite for the parameterised convection simulation (Fig. 8c) indicates generally weaker winds than seen in the explicit simulation. However, the maximum cold-pool winds (which clearly show a positive anomaly in Fig. 8b) are relatively weak, reaching maximum composite values of between 6 and $8 \mathrm{~m} \mathrm{~s}^{-1}$. This is lower than the mean maximum wind seen in Provod et al. (2016) for observed Sahelian cold pools of 8 to $10 \mathrm{~m} \mathrm{~s}^{-1}$. As the values in the centre (and just north of centre) of the domain would be most likely to be affected by almost all cold pools generated, it would be expected that there would be only a minor effect of reducing the wind speed values via compositing. With this in mind, it is surprising that the maximum value measured would be approximately $8 \mathrm{~m} \mathrm{~s}^{-1}$ as this represents only a minor exceedance of (or even a failure to exceed) the approximate $7-8 \mathrm{~m} \mathrm{~s}^{-1}$ dust uplift threshold used in many emission schemes (Marticorena et al., 1997). This suggests that, although there are clearly cold pools being generated in the convection permitting simulation, and these cold pools produce anomalously strong winds, they are not as strong as might be expected. Certainly the strongest cold-pools winds, which are known to generate the extreme 
(a)

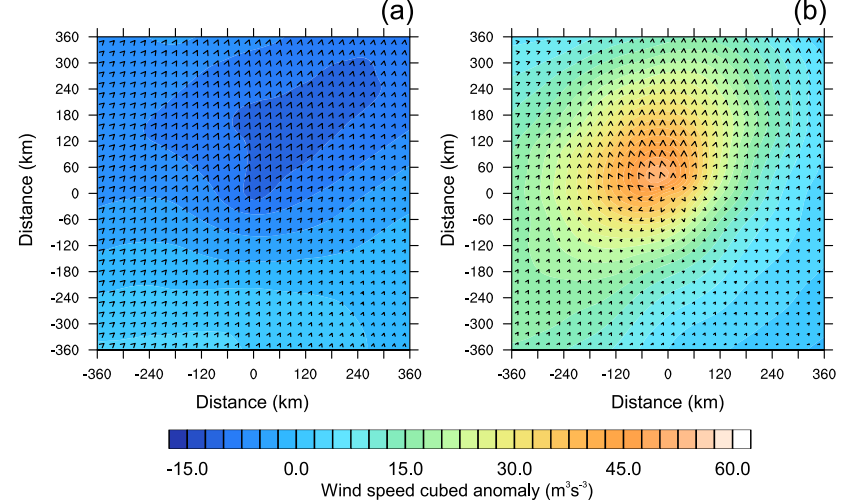

(c)

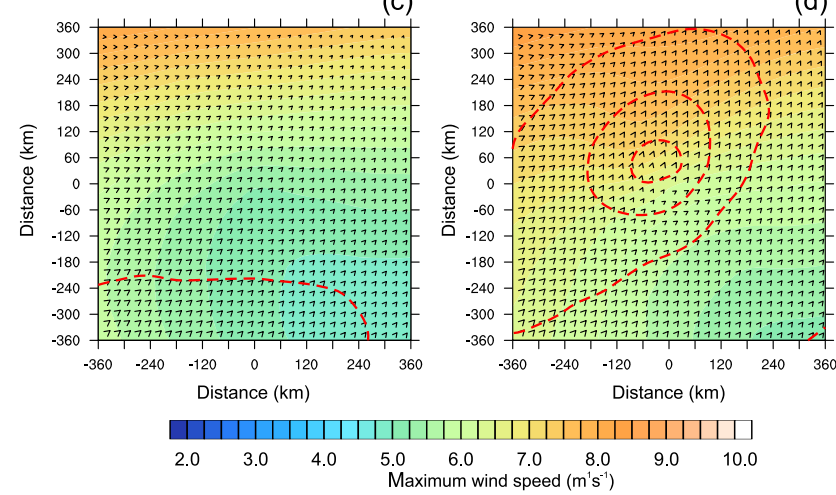

Figure 8. Composites around column rainfall exceeding $1 \mathrm{~mm} \mathrm{~h}^{-1}$. Composited time includes the point of threshold exceedance and the following $6 \mathrm{~h}$ of the simulation. Panels $(\mathbf{a}, \mathbf{b})$ show the wind speed cubed anomaly for $12 \mathrm{~km}$ simulations with parameterised and explicit convection respectively, arrows represent wind anomaly. Panels (c, d) show composites of the maximum wind speed in the rainfall to rainfall $+6 \mathrm{~h}$ window for $12 \mathrm{~km}$ simulations with parameterised and explicit convection; arrows represent composite winds and red dashed lines represent wind speed cubed anomaly at $15 \mathrm{~m}^{3} \mathrm{~s}^{-3}$ interval.

winds in the southern Sahara and Sahel stations, are missing in the models (Fig. 7).

The unchanging overall frequency of different wind speeds (Fig. 7) and the presence of convectively generated cold pools (Fig. 8) can be combined with the findings of Marsham et al. (2013) that up to $50 \%$ of dust emission in the summertime central Saharan hotspot occurs at night due to haboobs. This highlights the need to compare diurnal cycles of the different simulations. Figure 9 shows the diurnal cycle of dust uplift potential (DUP; Marsham et al., 2011) for all simulated months for the five sites for which there are observations. The northern Sahara station, F-138, has a similar development of the diurnal cycle across the 5 simulated months: in both observations and simulations the highest DUP values tend to occur during the day with much lower values at night, and in some months there is a maximum at 09:00 UTC, likely from the breakdown of the nocturnal LLJ. This is as expected given that F-138 is too far north to be strongly or regularly influenced by the cold pools spreading deep into the Sahara. The low night-time values reflect the development of a stable nocturnal boundary layer, which breaks down due to surface heating during daylight hours. F-134 and BBM in the Saharan box show a clearer peak from LLJ breakdown at approximately 09:00 UTC. At F134 (in both observations and simulations) this process is the dominant feature throughout the entire season. However, further south at BBM, the observations suggest that the morning peak in DUP is similar in magnitude, with an evening peak, in agreement with Marsham et al. (2013). This second peak in DUP associated with haboobs is not well represented in the simulations with the $12 \mathrm{~km}$ explicit and $4 \mathrm{~km}$ explicit simulations having different diurnal cycles with regard to the evening peak. This is possibly caused by the simulations failing to produce cold pools of sufficient strength as far north as BBM. However, the evening peak at BBM cannot be wholly attributed to cold pools. This is due to the fact that there is a similar, yet smaller, peak present in the simulations, with parameterised convection in June. This is feasibly the impact of the daily night-time surge of the monsoon flow, which is stronger in the parameterised simulations than the explicit simulations (consistent with Birch et al., 2014).

At the Sahelian stations of Agoufou and Kobou, the diurnal cycle in May (Fig. 9p, u) is similar to that seen in the Sahara with a morning LLJ peak in DUP and largely similar diurnal behaviour across all simulations. However, by June there is evidence of divergent behaviour between the simulations. At Agoufou and Kobou (Fig. 9q, v) there is an evening peak in DUP at 16:00-21:00 UTC, which is more pronounced in convection-permitting simulations. This evening peak grows more pronounced at these stations from July to August. This evening peak is also particularly noisy: this behaviour is what would be expected from high DUP values associated with cold pools due to their production of very high wind values that last on timescales $<1 \mathrm{~h}$ (for observations at a fixed point). When combined, these features mean that an average diurnal cycle produced over a relatively short period of time (1 month) will not produce a smooth evening peak in DUP. Concomitantly the convection-permitting simulations also have a reduction in size of the morning NLLJ DUP peak (consistent with Marsham et al., 2011). As shown earlier in Fig. 7 there is little change in the overall distribution of modelled wind speed with explicit convection, showing how the increased evening winds are compensated for by the decreasing morning winds overall.

Given that it has been shown that convective cold pools are present and are likely to be responsible for a significant modification of the diurnal cycle of winds in the Sahel and as far north as BBM it follows that there should be some modification in the uplift and transport of dust. Figure 10 shows the monthly mean diurnal cycle in dust emissions from the $12 \mathrm{~km}$ simulations for the five stations. Although there is some evidence of an evening increase in emissions in the convectionpermitting model at BBM in June-August, consistent with 

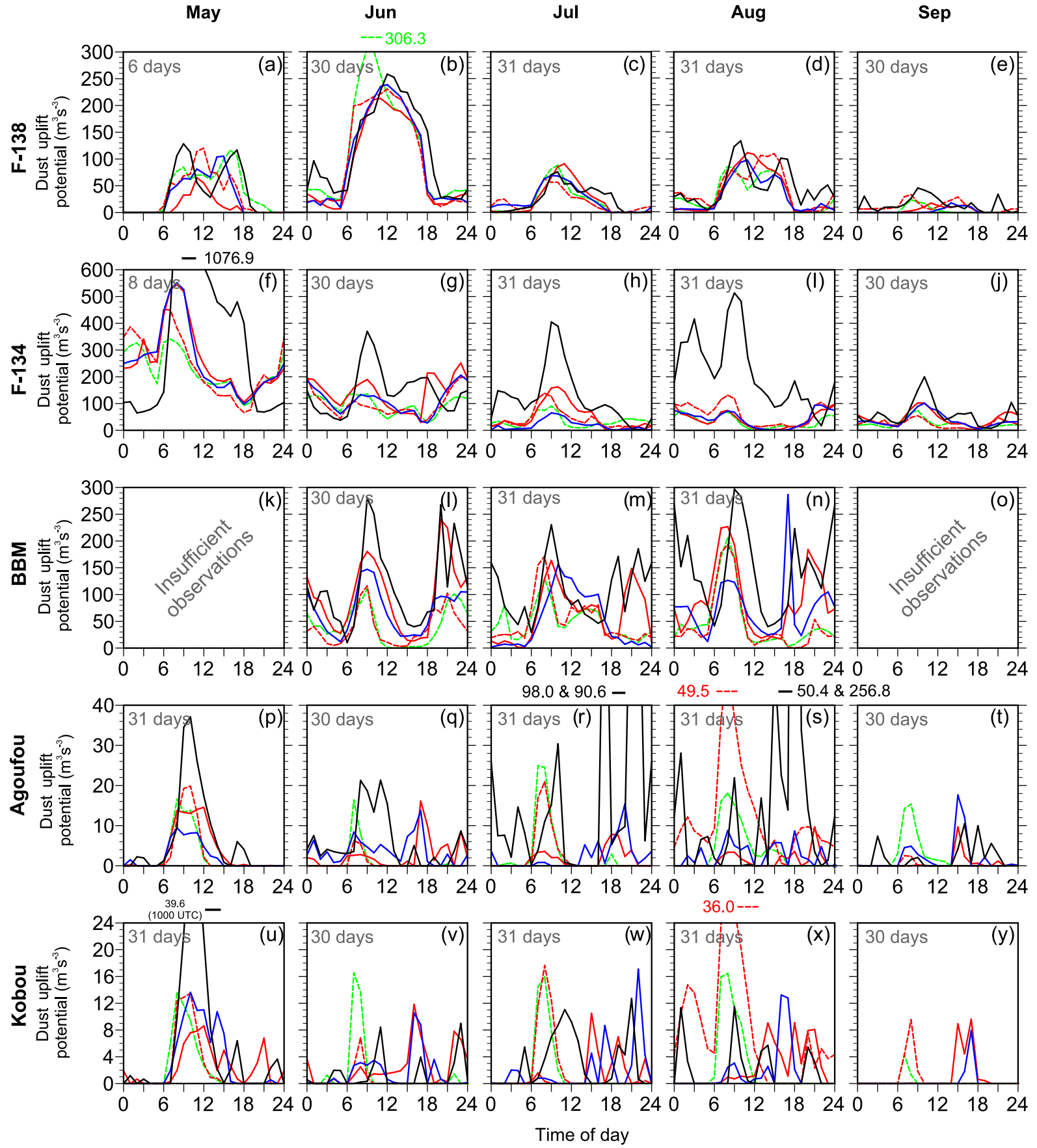

Figure 9. Diurnal cycle of dust uplift potential at the five observation stations for all 5 simulated months. Colours and dashed lines are the same as Fig. 7 (black is observations, green is $40 \mathrm{~km}$ simulation, red is $12 \mathrm{~km}$ simulations and blue is $4 \mathrm{~km}$ simulation, dashed lines indicate parameterisation of convection and solid lines indicate explicit convection). Where fewer than 5 days with data were available the diurnal cycle has not been calculated. For clarity the number of days with data has been shown for each panel.

the DUP in Fig. 9, this is insufficient to significantly change or improve the dust load and AOD. Dust emissions at stations in the Sahel (Agoufou and Kobou) are reduced in the explicit version: this is likely to be due to the increased soil moisture in that region (as demonstrated in Fig. 6). In addi- tion to such limits imposed by the surface characteristics on the uplift of dust in the model, it is also possible that there is some behaviour of convective storms and their associated cold pools that means that they do not lift dust; for example 

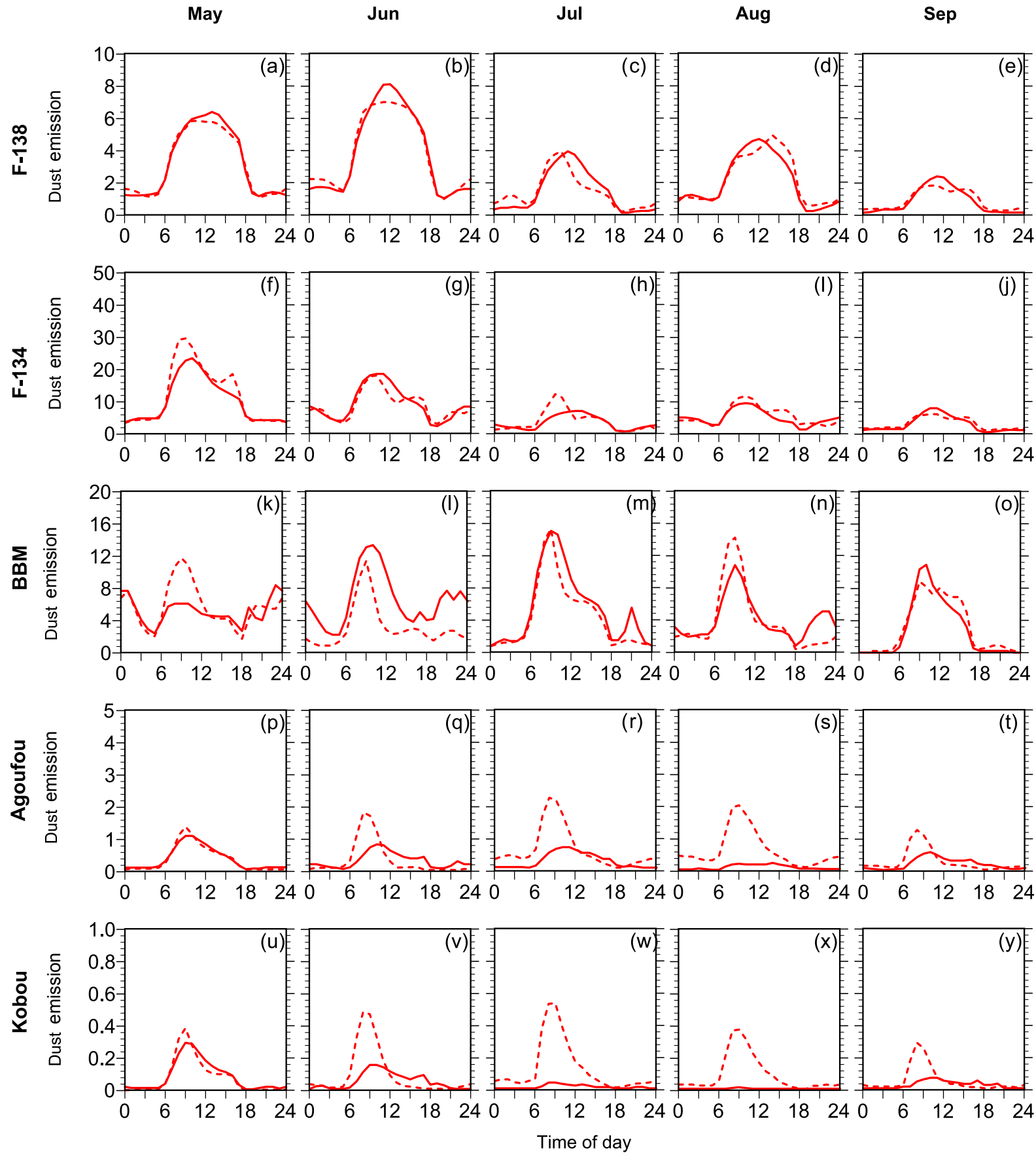

Figure 10. Monthly mean (May-September) diurnal cycles in dust emission (in $\mu \mathrm{g} \mathrm{m}^{2} \mathrm{~s}^{-1}$ ) for Fennec and AMMA stations (shown on Fig. 1) for $12 \mathrm{~km}$ models with explicit (12E, red solid line) and parameterised (12P, red dashed line) convection. (a-e) Fennec station F138, (f-j) Fennec station F-134, (k-o) Fennec supersite at Bordj Badji Mokhtar, (p-t) AMMA CATCH site at Agoufou and (u-y) AMMA $\mathrm{CATCH}$ site at Kobou. Note the changing vertical scale for each location.

the wrong size, lifetime or location. This is examined in the next section.

\subsection{Impact of resolving convection on modelled storms}

To investigate the nature of the storms that are responsible for the generation of cold pools, a storm-tracking approach has been used. This takes advantage of the availability of satellite 

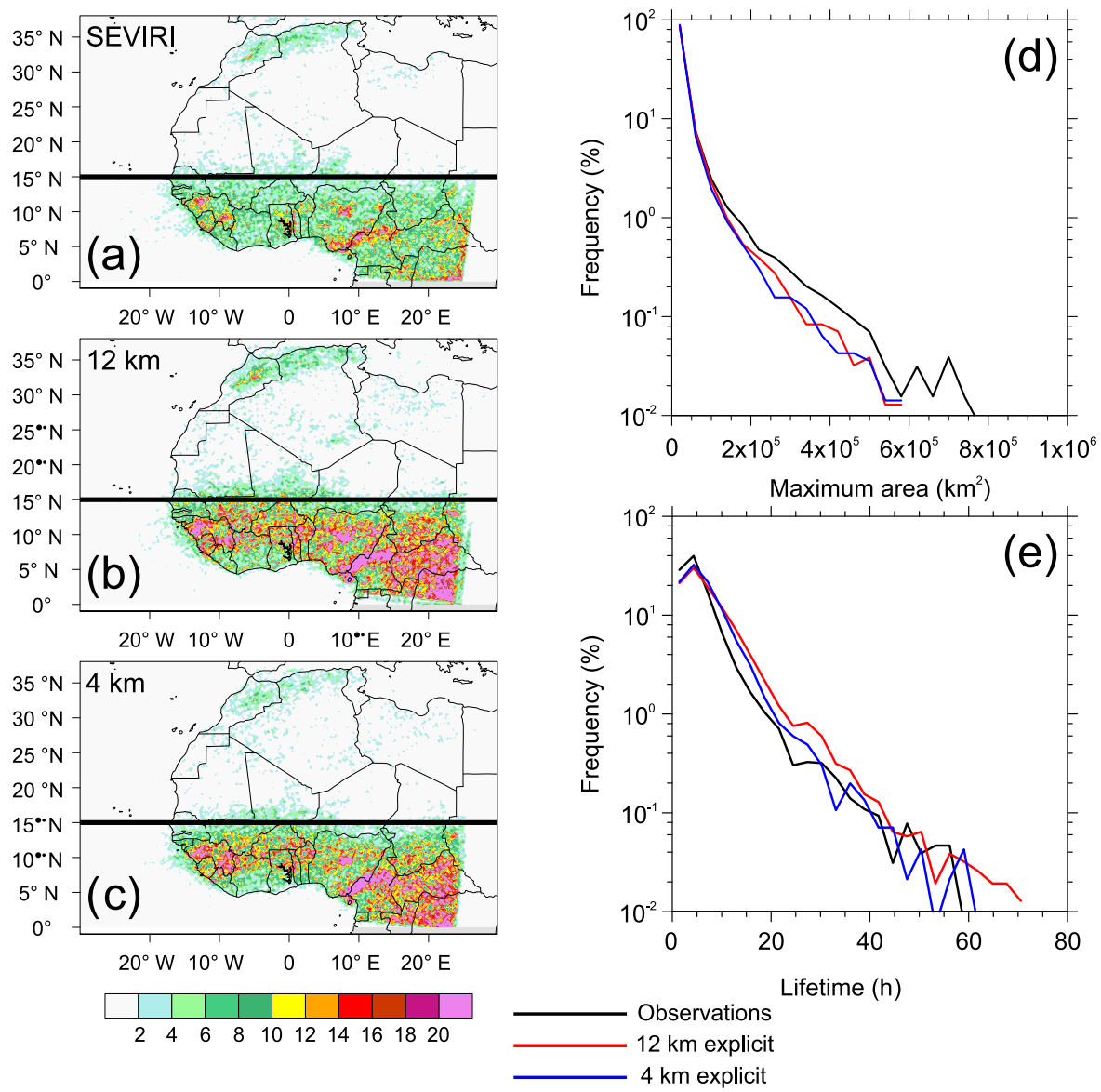

Figure 11. Storm-tracking mesoscale convective system (MCS) track density for (a) observed MCSs, (b) MCSs in the $12 \mathrm{~km}$ convection permitting simulation and (c) MCSs in the $4 \mathrm{~km}$ convection-permitting simulation. Area and lifetime distributions for the tracked MCSs are also shown in $(\mathbf{d}, \mathbf{e}) .15^{\circ} \mathrm{N}$ is highlighted on the track density plots (a-c) to aid in the interpretation between tracks obtained from observations and those from simulations in the marginal region where the amount of dust is known to be raised in reality but is not raised in the simulations.

observations of outgoing long-wave radiation from which the brightness temperature can be easily derived, and tracking is performed on features with a brightness temperature below $-40^{\circ} \mathrm{C}$. This means that direct comparisons of the storms produced in the convection-permitting simulations can be made with those identified through satellite retrievals. To reduce the number of events that were considered and to highlight the impact of larger events which dominate observed dust uplift in the central summertime Sahara (Marsham et al., 2013; Allen et al., 2013), only storms that reached a threshold value in size (approximately $5000 \mathrm{~km}^{2}$ ) were considered. These systems will be referred to as mesoscale convective systems (MCSs) hereafter. The total number of MCSs between the 4 and $12 \mathrm{~km}$ convection-permitting simulations and the observations is not dissimilar, having 14,082, 15,555 and 12,843 respectively; however, the storm track densities (number of times a storm track is centred over a specific region on a $0.25^{\circ}$ grid) in Fig. $11 \mathrm{a}-\mathrm{c}$ shows that there is a greater density of events in both of the simulations compared to the observations. This is likely due to the generally enhanced lifetime of MCSs seen in simulations (Fig. 11e). The spatial distribution of MCS track density (based on storm centres) indicates that their latitudinal position in simulations compared to reality is approximately correct, with MCSs (and therefore cold pools) commonly occurring as far as $17^{\circ} \mathrm{N}$, indicating that the positioning of the MCSs is not the driving factor behind the lack of dust raised here. However, the higher frequency of very large storms in SEVIRI imagery compared to explicit simulations (Fig. 11d), the generally weak cold-pool winds identified in Fig. 8d and the missing tail of high winds in Fig. 7b, c, suggest that the region affected by large cold pools has an underrepresentation of coldpool winds in convection-permitting simulations.

Figure 11e shows the distributions of the MCS duration (to the nearest hour), highlighting the fact that the 4 and $12 \mathrm{~km}$ simulations have MCSs that last longer on average than those 

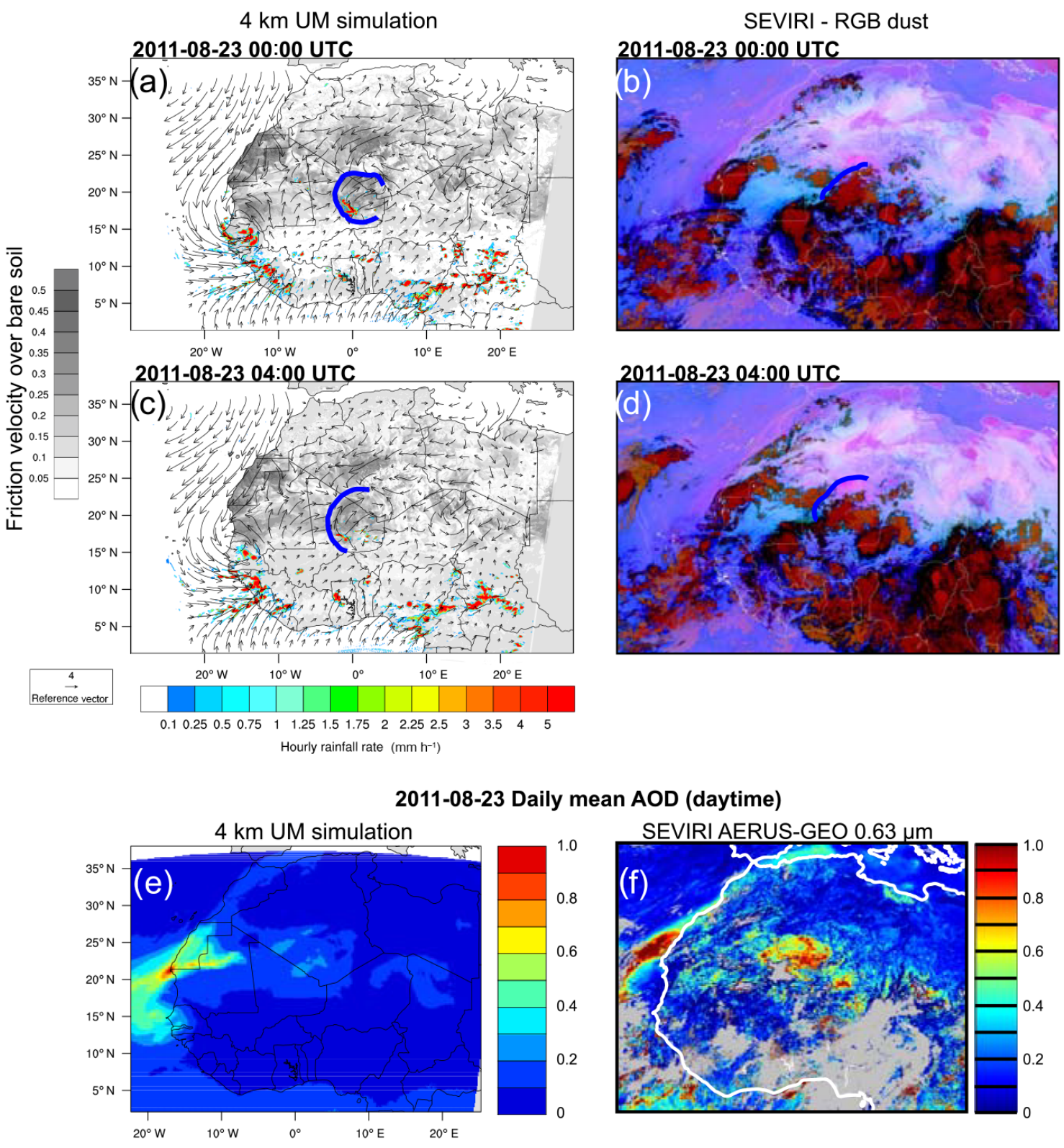

Figure 12. Case study of a large cold-pool event that occurred on the morning of 23 August 2011 that is present both in the observations and in the $4 \mathrm{~km}$ explicit simulation. Panels (a, c) show simulated rainfall (colours), $10 \mathrm{~m}$ wind (vectors) and friction velocity over bare soil (grey shading, a key feature in the emission of dust within the model). Panels (b, d) show SEVIRI false colour RGB dust imagery for the same times as panels (a, c). The leading edge of the cold pool has been highlighted in blue where visible on both plots of the simulation and SEVIRI images. Panels (e, f) show simulated and observed AOD values (daytime means) for the day of the haboob. Observed AOD is from the SEVIRI AERUS-GEO AOD product.

in SEVIRI; it is only storms that live beyond $30 \mathrm{~h}$ for the $4 \mathrm{~km}$ simulations and $47 \mathrm{~h}$ for the $12 \mathrm{~km}$ simulations that the frequency of occurrence first drops below the values seen from observations. This abundance of events (even MCSs that are smaller than those observed) and the fact that convective cold pools are clearly being produced in the simulations (despite their reduced strength) suggests that the lack of emission in the simulation south of $17^{\circ} \mathrm{N}$ cannot, however, be entirely at- tributed to smaller MCSs producing smaller and weaker cold pools.

In interpreting the storm-track-based analysis discussed above, it is useful to examine sample images of observed and modelled large storms. Figure 12 is a case study of a large cold-pool event that occurred on 23 August 2011. It was well represented in the $4 \mathrm{~km}$ simulation in that the timing and location of initiation of the system was roughly correct, af- 
ter which a large MCS developed and produced a cold pool which spread north and west into the Sahara. Although we do not necessarily expect an accurate one-to-one correspondence between observed and modelled storms this far into the simulation, the case shown does share key similarities and is one of the larger modelled storms from the simulated period. The cold pool in the simulation can be seen through both the elevated friction velocity over bare soil as well as the spreading of air away from the MCS shown in the $10 \mathrm{~m}$ wind vectors. Similarly, the cold pool generated in reality can be identified through the occurrence of arc clouds along the leading edge of the cold pool and the magenta colour that identifies raised dust within the cold pool in the SEVIRI RGB false colour dust images. The impact that this cold pool has on dust is assessed through the daytime averages of the dust AOD from the $4 \mathrm{~km}$ simulation and the SEVIRI AERUSGEO AOD product. There is clearly a strong AOD signal associated with the cold pools in both measures. However, the signal in the simulation is dwarfed by the high levels over the western part of the domain (at least partially associated with erroneously high uplift over the Western Sahara). In the SEVIRI AERUS-GEO product the AOD feature in the central Sahara is comparable in magnitude to the transported plume over the Atlantic and is much more clearly linked to uplift caused by strong near-surface winds associated with the passage of a convective cold pool. This is consistent with the maximum mean hourly observed wind on this day at BBM being $11.4 \mathrm{~m} \mathrm{~s}^{-1}$ and the maximum instantaneous modelled cold-pool wind being $7.5 \mathrm{~m} \mathrm{~s}^{-1}$.

\section{Conclusions}

We have investigated whether biases in dust AOD over the Sahara and Sahel, known to exist in many global and regional models, can be improved in the Met Office Unified Model (UM) by using an explicit rather than parameterised formulation of convection. It was hypothesised that explicit resolution of the strong winds associated with cold-pool outflows which generate dust storms (haboobs) in summertime West Africa might enhance the AOD in the central Saharan heat low (SHL) region, where haboobs have been observed to be a key uplift mechanism and where a dust maximum is present in satellite retrievals but missing in many models. Regional versions of the UM with prognostic dust at 4,12 and $40 \mathrm{~km}$ grid spacings were used, with explicit convection at 4 and $12 \mathrm{~km}$ and parameterised convection at 12 and $40 \mathrm{~km}$. These SWAMMA simulations enable a clean comparison between models at $12 \mathrm{~km}$ resolution with explicit and parameterised convection (differing only in representation of convection). This provides a seamless approach, with the model configurations ranging from high-resolution $(4 \mathrm{~km})$ convectionpermitting to a configuration similar to a climate model. In this respect a potentially valuable property of the SWAMMA simulations is their similarity with CMIP5 simulations in be- haviour and AOD features, indicating that investigation of process errors in SWAMMA are likely to identify and provide knowledge about similar errors in the CMIP5 data set.

The results show that all SWAMMA simulations have very similar dust AOD fields, despite explicit convection significantly changing the wind fields and overall clearly demonstrate how improving the representation of cold pools, known to be critical to dust uplift, is a necessary but not sufficient condition for improving AOD fields. When convection is modelled explicitly, cold pools (haboobs) are present and the diurnal cycle in surface winds is better represented. However, in the southern Sahara the rare very strong wind events that result from haboobs and cause the most intense dust storms are still absent in all simulations. The analysis of composite cold pools and storm tracking shows that, although storms exist far enough north in convection-permitting simulations, the storms are not sufficiently large, which is likely to limit both the intensity of the cold-pool winds and the northwards propagation of the resultant cold pools into the southern Sahara, and so it is consistent with the weaker than observed winds in that key region. This interpretation is supported by a simple representative case study of a large storm that shows how in the model, even when a large system is generated it does not raise quantities of dust comparable to those seen in satellite retrievals. Consistent with past studies of longduration large-domain runs, in the explicit runs there is a reduction in the strength of the morning low-level jet (LLJ), which compensates for the haboob uplift. This means that the increase in dust emissions achieved by the strengthened evening (haboob) winds does not produce any overall increase in the AOD in the SHL region, since the LLJ winds are reduced. The results here likely contrast with those of Chaboureau et al. (2016), where explicit haboobs did improve dust fields for several reasons: (i) in the Chaboureau set-up it is not expected that the explicit convection weakens the low-level jet because their simulations are initialised daily and run for between 24 and $72 \mathrm{~h}$ depending on the model (as seen in comparisons between 2-day and 10-day runs in Marsham et al., 2011), (ii) the Chaboureau models have a different land surface to the UM and different dust emission schemes which are individually tuned so that AOD changes cannot be attributed solely to the choice of convection scheme and (iii) the Chaboureau models with explicit convection have a more limited southern boundary than the SWAMMA simulation so their results are more focussed on Saharan rather than on Sahelian dust (results are shown for the region $13-31^{\circ} \mathrm{N}$ ).

The results here also suggest several key problems with the modelled land surface in the UM. The models have almost no dust uplift in the Sahel, whereas in reality convective storms over the Sahel do raise dust (Flamant et al., 2007; Marsham et al., 2009; Roberts and Knippertz, 2014). South of $15^{\circ} \mathrm{N}$ the models have a low and temporally unvarying bare-soil fraction which is unable to release sufficient dust even if surface conditions and winds are favourable; in reality it is known 
that the Sahel has a large variation in the bare-soil fraction seasonally and interannually (Mougin et al., 2009). The use of soil moisture in the model is also implicated, since the model uses soil moisture over a $10 \mathrm{~cm}$ layer, whereas in reality it is the skin soil moisture that is relevant and both the soil make-up (sandy soils) and the hot, dry conditions in the northern Sahel and Sahara mean that the actual time between rainfall and dust emission can be much shorter than that predicted by the SWAMMA simulations (Gillette et al., 2001; Bergametti et al., 2016). This role of the land surface errors in the Sahel is consistent with recent analysis of operational global UM runs (Pope et al., 2016). Finally, the clay fraction is a crucial soil texture parameter in several of the dust emission and flux calculations and high clay fractions over the west coast in combination with strong northerly winds blowing off the Atlantic cause high AOD values there which are not seen in observations.

The issues discussed above provide a stark demonstration of the number of marginal processes that must be well simulated in any model to capture the seasonal evolution of the dust field over Africa. Models must capture the seasonal evolution of the continental-scale thermodynamics gradients, which is itself non-trivial and dependent on convection (Marsham et al., 2013); the location of the moist convection, particularly the marginal convection close to both the leading edge of the monsoon and close to the sharp gradient in soil moisture and vegetation present from the Sahel to the Sahara; the tail of strong winds from cold pools and the lowlevel jet breakdown; the time evolution of skin soil moisture and vegetation (and therefore roughness); and the soil properties themselves. Given these challenges it is perhaps not surprising that Evan et al. (2014) conclude that the CMIP models are unable to capture any of the salient features of northern African dust emission and transport. An improved representation of cold pools in dust models is clearly necessary but not in itself sufficient for improving AOD fields within the UM. Future evaluations of dust models should ensure that winds as well as dust are evaluated to ensure that models are getting the right answers for the right reasons (noting the value of observed not analysed winds due to the large biases in analyses). Although parameterisations of haboobs (e.g. Pantillon, 2015, 2016) are clearly valuable, corresponding improvements are also needed in soil moisture, vegetation and soil properties in models. There is a need for potential scale dependences for maximum wind speeds in convection-permitting models to be investigated. It is also clear that winds from explicit models (the UM and potentially other models) may still have significant biases, even though haboobs are represented. Therefore estimates of the fraction of dust uplift from haboobs from such models (e.g. Heinold et al., 2013), although very valuable, may be a significant underestimate and must be treated with caution.
Data availability. As yet the SWAMMA and Fennec data have not been moved into long-term storage. However data are available on request. For more information please contact Alexander J. Roberts via the author correspondence address.

Competing interests. The authors declare that they have no conflict of interest.

Acknowledgements. We would first like to thank the anonymous reviewers and the co-editor, Yves Balkanski, for their valuable insight and help in improving this paper. The SWAMMA project was funded by the UK Natural Environmental Research Council (NERC) standard grant NE/L005352/1. John Marsham was also funded by AMMA 2050 (NE/M020126/1), IMPALA (NE/M017176/1) and DACCIWA (FP7/2007-2013 under grant agreement no. 603502). This work used the ARCHER UK National Supercomputing Service (http://www.archer.ac.uk) to perform the model experiments and the JASMIN super-data-cluster (https://doi.org/10.1109/BigData.2013.6691556) at the Centre for Environmental Data Archival (CEDA) for longer-term storage and analysis of model output. The assistance of Grenville Lister at NCAS-CMS Reading in facilitating the model runs is gratefully acknowledged. We also thank Stephanie Woodward (UK Met Office Hadley Centre) and Cathryn Birch (University of Leeds) for their advice with various aspects of the model set-up. MODIS AOD analyses used in this paper were produced with the Giovanni online data system, developed and maintained by the NASA GES DISC. We are grateful to EUMETSAT for SEVIRI data used for storm tracking. SEVIRI RGB dust imagery is available from http://www.fennec.imperial.ac.uk and SEVIRI AERUS GEO AOD imagery is available from the ICARE Data and Services Center www.icare.univ-lille1.fr. The Fennec AWS network was developed, tested and installed as part of the Fennec project (NE/G017166/1). The AMMA-CATCH system was funded by the French Ministry of Research and National Institute for Earth Sciences and Astronomy.

Edited by: Yves Balkanski

Reviewed by: two anonymous referees

\section{References}

Acker, J. G. and Leptoukh, G.: Online Analysis Enhances Use of NASA Earth Science Data, Eos, Trans. AGU, 88, 14-15, 2007.

Ackerley, D. Joshi, M. M., Highwood, E. J., Ryder, C. L., Harrison, M. A. J., Walters, D. N., Milton, S. F., and Strachan, J.: A Comparison of Two Dust Uplift Schemes within the Same General Circulation Model, Adv. Meteorol., 13, https://doi.org/10.1155/2012/260515, 260515, 2012.

Allen, C. J. T., Washington, R., and Engelstaedter, S.: Dust emission and transport mechanisms in the central Sahara: Fennec groundbased observations from Bordj Badji Mokhtar, June 2011, J. Geophys. Res.-Atmos., 118, 6212-6232, 2013.

Allen, C. J. T. and Washington, R.: The low-level jet dust emission mechanism in the central Sahara: Observations from Bordj-Badji Mokhtar during the June 2011 Fennec Intensive Observation Period, J. Geophys. Res.-Atmos., 119, 2990-3015, 2014. 
Bergametti, G., Rajot, J. L., Pierre, C., Bouet, C., and Marticorena, B.: How long does precipitation inhibit wind erosion in the Sahel?, Geophys. Res. Lett., 43, 6643-6649, 2016.

Best, M. J.: Unified Model Documentation Paper 025 Canopy, Surface Soil Hydrol., Met Office, Exeter, UK, 2005.

Best, M. J., Pryor, M., Clark, D. B., Rooney, G. G., Essery, R. L. H., Ménard, C. B., Edwards, J. M., Hendry, M. A., Porson, A., Gedney, N., Mercado, L. M., Sitch, S., Blyth, E., Boucher, O., Cox, P. M., Grimmond, C. S. B., and Harding, R. J.: The Joint UK Land Environment Simulator (JULES), model description Part 1: Energy and water fluxes, Geosci. Model Dev., 4, 677-699, https://doi.org/10.5194/gmd-4-677-2011, 2011.

Birch, C. E., Parker, D. J., Marsham, J. H., Copsey, D., and GarciaCarreras, L.: A seamless assessment of the role of convection in the water cycle of the West African Monsoon, J. Geophys. Res.Atmos., 119, 2890-2912, 2014.

Brindley, H., Knippertz, P., Ryder, C., and Ashpole, I.: A critical evaluation of the ability of the Spinning Enhanced Visible and Infrared Imager (SEVIRI) thermal infrared red-green-blue rendering to identify dust events: Theoretical analysis, J. Geophys. Res., 117, D07201, https://doi.org/10.1029/2011JD017326, 2012.

Carrer, D., Roujean, J.-L., Hautecoeur, O., and Elias, T.: Daily estimates of aerosol optical thickness over land surface based on a directional and temporal analysis of SEVIRI MSG visible observations, J. Geophys. Res., 115, D10208, https://doi.org/10.1029/2009JD012272, 2010.

Carrer, D., Ceamanos, X., Six, B., and Roujean, J.-L.: AERUSGEO: A newly available satellite-derived aerosol optical depth product over Europe and Africa, Geophys. Res. Lett., 41, 77317738, 2014.

Chaboureau, J.-P., Flamant, C., Dauhut, T., Kocha, C., Lafore, J.P., Lavaysse, C., Marnas, F., Mokhtari, M., Pelon, J., Reinares Martínez, I., Schepanski, K., and Tulet, P.: Fennec dust forecast intercomparison over the Sahara in June 2011, Atmos. Chem. Phys., 16, 6977-6995, https://doi.org/10.5194/acp-166977-2016, 2016.

Cowie, S. M., Marsham J. H., and Knippertz, P.: The importance of rare, high-wind events for dust uplift in northern Africa, Geophys. Res. Lett., 42, 8208-8215, 2015.

Crook, J. and co-authors, in preparation: Assessment of the Representation of Storm Lifecycles in Convection Permitting Simulations, in preparation, 2018.

Davies, T., Cullen, M. J. P., Malcolm, A. J., Mawson, M. H., Staniforth, A., White, A. A., and Wood, N.: A new dynamical core for the Met Office's global and regional modelling of the atmosphere, Q. J. R. Meteorol. Soc., 131, 1759-1782, 2005.

Edwards, J. M., Manners, J., Thelen, J. C., Ingram, W. J., and Hill, P. G.: Unified Model Documentation Paper 023 The Radiation Code, Met Office, Exeter, UK, 2012.

Englestaedter, S. and Washington, R.: Atmospheric controls on the annual cycle of North African dust, J. Geophys. Res.-Atmos., 112 D3, https://doi.org/10.1029/2006JD007195, 2007.

Evan, A. T., Flamant, C., Fiedler, S., and Doherty, O.: An analysis of aeolian dust in climate models, Geophys. Res. Lett., 41, 59966001, 2014.

FAO: Harmonized World Soil Database (version 1.2). Food Agriculture Organization, Rome, Italy and IIASA, Laxenburg, Austria, 2012.
Fiedler, S., Schepanski, K., Heinold, B., Knippertz, P., and Tegen, I.: Climatology of nocturnal low-level jets over North Africa and implications for modeling mineral dust emission, J. Geophys. Res.-Atmos., 118, 6100-6121, 2013.

Flamant, C., Chaboureau, J.-P., Parker, D. J., Taylor, C. M., Cammas, J.-P., Bock, O., Timouk, F., and Pelon, J.: Airborne observations of the impact of a convective system on the planetary boundary layer thermodynamics and aerosol distribution on the inter-tropical discontinuity region of the West African Monsoon, Q. J. R. Met. Soc., 133, 1175-1189, 2007.

Garcia-Carreras, L., Marsham, J. H., Parker, D. J., Bain, C. L., Milton, S., Saci, A., Salah-Ferroudj, M., Ouchene, B., and Washington, R.: The impact of convective cold pool outflows on model biases in the Sahara, Geophys. Res. Lett., 40, 1647-1652, 2013.

Ginoux, P., Prospero, J. M., Gill, T. E., Hsu, N. C., and Zhao, M.: Global-scale attribution of anthropogenic and natural dust sources and their emission rates based on MODIS Deep Blue aerosol products, Rev. Geophys., 50, RG3005, 2012.

Gillette, D. A., Niemeyer, T. C., and Helm, P. J.: Supply-limited horizontal sand drift at an ephemerally crusted, unvegetated saline playa, J. Geophys. Res., 106, P148085-P18098, 2001.

Haywood, J. M., Allan, R. P., Culverwell, I., Slingo, T., Milton, S., Edwards, J., and Clerbaux, N.: Can desert dust explain the outgoing longwave radiation anomaly over the Sahara during July 2003?, J. Geophys. Res., 110, D05105, https://doi.org/10.1029/2004JD005232, 2005.

Heinold, B., Knippertz, P., Marsham, J. H., Fiedler, S., Dixon, N. S., Schepanski, K., Laurent, B., and Tegen, I.: The role of deep convection and nocturnal low-level jets for dust emission in summertime West Africa: Estimates from convection permitting simulations, J. Geophys. Res.-Atmos., 118, 4385-4400, 2013.

Hobby, M., Gascoyne, M., Marsham, J. H., Bart, M., Allen, C., Engelstaedter, S., Fadel, D. M., Gandega, A., Lane, R., McQuaid, J. B., Ouchene, B., Ouladichir, A., Parker, D. J., Rosenberg, P., Ferroudj, M. S., Saci, A., Seddik, F., Todd, M., Walker, D., and Washington, R.: The Fennec Automatic Weather Station (AWS) Network: Monitoring the Saharan Climate System, J. Atmos. Oceanic Tech., 30, 709-724, 2013.

Huang, Q., Marsham, J. H., Tian, W., Parker, D. J., and GarciaCarreras, L.: Large-eddy simulation of dust-uplift by a haboob density current, Atmos. Environ., 179, 31-39, 2018.

Huneeus, N., Schulz, M., Balkanski, Y., Griesfeller, J., Prospero, J., Kinne, S., Bauer, S., Boucher, O., Chin, M., Dentener, F., Diehl, T., Easter, R., Fillmore, D., Ghan, S., Ginoux, P., Grini, A., Horowitz, L., Koch, D., Krol, M. C., Landing, W., Liu, X., Mahowald, N., Miller, R., Morcrette, J.-J., Myhre, G., Penner, J., Perlwitz, J., Stier, P., Takemura, T., and Zender, C. S.: Global dust model intercomparison in AeroCom phase I, Atmos. Chem. Phys., 11, 7781-7816, https://doi.org/10.5194/acp11-7781-2011, 2011.

Huneeus, N., Basart, S., Fiedler, S., Morcrette, J.-J., Benedetti, A., Mulcahy, J., Terradellas, E., Pérez García-Pando, C., Pejanovic, G., Nickovic, S., Arsenovic, P., Schulz, M., Cuevas, E., Baldasano, J. M., Pey, J., Remy, S., and Cvetkovic, B.: Forecasting the northern African dust outbreak towards Europe in April 2011: a model intercomparison, Atmos. Chem. Phys., 16, 4967-4986, https://doi.org/10.5194/acp-16-4967-2016, 2016.

Hsu, N. C., Jeong, M.-J., Bettenhausen, C., Sayer, A. M., Hansell, R., Seftor, C. S., Huang, J., and Tsay, S.-C.: Enhanced Deep Blue 
aerosol retrieval algorithm: The second generation, J. Geophys. Res.-Atmos., 118, 9296-9315, 2013.

Johnson, B. T., Brooks, M. E., Walters D., Woodward, S., Christopher, S., and Schepanski, K.: Assessment of the Met Office dust forecast model using observations from the GERBILS campaign, Q. J. R. Meteorol. Soc., 137, 1131-1148, 2011.

Johnson, B. T. and Osborne, S. R.: Physical and optical properties of mineral dust aerosol measured by aircraft during the GERBILS campaign, Q. J. R. Meteorol. Soc., 137, 1117-1130, 2011.

Johnson, C. E., Bellouin, N., Davison, P. S., Jones, A., Rae, J. G. L., Roberts, D. L., Woodage, M. J., Woodward, S., Ordonez, C., and Savage, N. H.: Unified Model Documentation Paper 020: CLASSIC Aerosol Scheme Version 5, Met Office, Exeter, UK, 2011.

Kinne, S., Lohmann, U., Feichter, J., Schultz, J., Timmreck, C., Ghan, S., Easter, R., Chin, M., Ginoux, P., Takemura, T., Tegen, I., Koch, D., Herzog, M., Penner, J., Pitari, G., Holben, B., Eck, T., Smirnov, A., Dubovik, O., Slutsker, I., Tanre, D., Torres, O., Mishchenko, M., Geogdzhayev, I., Chu, D. A., and Kaufman, Y.: Monthly averages of aerosol properties: A global comparison among models, satellite data, and AERONET ground data, J. Geophys. Res.-Atmos., 108, 4634, 2003.

Klose, M., Shao, Y., Karremann, M. K., and Fink, A.: Sahel dust zone and synoptic background, Geophys. Res. Lett., 37, L09802, https://doi.org/10.1029/2010GL042816, 2010.

Knippertz, P.: Dust emissions in the West African heat trough - The role of the diurnal cycle and of extratropical disturbances, Meteorol. Z., 17, 553-563, 2008.

Knippertz, P. and Todd, M.: The central west Saharan dust hot spot and its relation to African easterly waves and extratropical disturbances, J. Geophys. Res.-Atmos., 115, D12, https://doi.org/10.1029/2009JD012819, 2010.

Knippertz, P. and Todd, M. C.: Mineral dust aerosols over the Sahara: Meteorological controls on emission and transport and implications for modeling, Rev. Geophys, 50, RG1007, https://doi.org/10.1029/2011RG000362, 2012.

Largeron, Y., Guichard, F., Bouniol, D., Couvreux, F., Kergoat, L., and Marticorena, B.: Can we use surface wind fields from meteorological reanalysis for Sahelian dust simulations?, Geophys. Res. Lett., 42, 2490-2499, 2015.

Lebel, T., Parker, D. J., Flamant, C., Höller, H., Polcher, J., Redelsperger, J.-L., Thorncroft, C., Bock, O., Bourles, B., Galle, S., Marticorena, B., Mougin, E., Peugeot, C., Cappelaere, B., Descroix, L., Diedhiou, A., Gaye, A., and Lafore, J.-P.: The AMMA field campaigns: accomplishments and lessons learned, Atmos. Sci. Lett., 12, 123-128, 2011.

Lock, A. and Edwards, J. M.: Unified Model Documentation Paper 024 The Parameterization of Boundary Layer Processes, Met Office, Exeter, UK, 2012.

Luo, C., Mahowald, N. M., and del Corral, J.: Sensitivity study of meteorological parameters on mineral aerosol mobilization, transport, and distribution, J. Geophys. Res., 108, 4447, https://doi.org/10.1029/2003JD003483, 2003.

Marsham, J. H., Parker, D. J., Grams, C. M., Taylor, C. M., and Haywood, J. M.: Uplift of Saharan dust south of the intertropical discontinuity, J. Geophys. Res.-Atmos., 113, D21102, https://doi.org/10.1029/2008JD009844, 2008.
Marsham, J. H., Grams, C. M., and Mühr, B.: Photographs of dust uplift from small scale atmospheric features, Weather, 64, 180 $181,2009$.

Marsham, J. H., Knippertz, P., Dixon, N. S., Parker, D. J., and Lister, G. M. S.: The importance of the representation of deep convection for modelled dust-generating winds over West Africa during summer, Geophys. Res. Lett., 38, L16803, https://doi.org/10.1029/2011GL048368, 2011.

Marsham, J. H., Hobby, M., Allen, C. J. T., Banks, J. R., Bart, M., Brooks, B. J., Cavazos-Guerra, C., Englestaedter, S., Gascoyne, M., Lima, A. R., Martins, J. V., McQuaid, J. B., O’Leary, A., Ouchene, B., Ouladichir, A., Parker, D. J., Saci, A., SalahFerroudj, M., Todd, M. C., and Washington, R.: Meteorology and dust in the central Sahara: Observations from Fennec supersite-1 during the June 2011 Intensive Observation Period, J. Geophys. Res.-Atmos., 118, 4069-4089, 2013.

Marticorena, B. and Bergametti, G.: Modeling the atmospheric dust cycle: 1 . Design of a soil-derived dust emission scheme, J. Geophys. Res., 100, 16415-16430, 1995.

Marticorena, B., Bergametti, G., Aumont, B., Callot, Y., N'Doumé, C., and Legrand, M.: Modeling the atmospheric dust cycle: 2. Simulation of Saharan dust sources, J. Geophys. Res., 102, 4387 4404, 1997.

Marticorena, B., Chatenet, B., Rajot, J. L., Traoré, S., Coulibaly, M., Diallo, A., Koné, I., Maman, A., NDiaye, T., and Zakou, A.: Temporal variability of mineral dust concentrations over West Africa: analyses of a pluriannual monitoring from the AMMA Sahelian Dust Transect, Atmos. Chem. Phys., 10, 8899-8915, https://doi.org/10.5194/acp-10-8899-2010, 2010.

Moufouma-Okia, W. and Jones, R. G.: Resolution dependence in simulating the African hydroclimate with the HadGEM3RA Regional Climate Model, Clim. Dynam., 44, 609-632, 2015.

Mougin, E., Hiernaux, P., Kergoat, L., Grippa, M., de Rosnay, P., Timouk, F., Le Dantec, V., Demarez, V., Lavenu, F., Arjounin, M., Lebel, T., Soumaguel, N., Ceschia, E., Mougenot, B., Baup, F., Frappart, F., Frison, P. L., Gardelle, J., Gruhier, C., Jarlan, L., Mangiarotti, S., Sanou, B., Tracol, Y., Guichard, F., Trichon, V., Diarra, L., Soumaré, A., Koité, M., Dembélé, F., Lloyd, C., Hanan, N. P., Damesin, C., Delon, C., Serça, D., Galy-Lacaux, C., Seghieri, J., Becerra, S., Dia, H., Gangneron, F., and Mazzega, P.: The AMMA-CATCH Gourma observatory site in Mali: Relating climatic variations to changes in vegetation, surface hydrology, fluxes and natural resources, J. Hydrol., 375, 14-33, 2009.

Ocko, I. B. and Ginoux, P. A.: Comparing multiple model-derived aerosol optical properties to spatially collocated ground-based and satellite measurements, Atmos. Chem. Phys., 17, 44514475, https://doi.org/10.5194/acp-17-4451-2017, 2017.

Ogawa, K. and Schmugge, T.: Mapping Surface Broadband Emissivity of the Sahara Desert Using ASTER and MODIS Data, Earth Interactions, 8, Paper 7, 2004.

Pantillon, F., Knippertz, P., Marsham, J. H., and Birch, C. E.: A Parameterization of Convective Dust Storms for Models with MassFlux Convection Schemes, J. Atmos. Sci., 72, 2545-2561, 2015.

Pantillon, F., Knippertz, P., Marsham, J. H., Panitz, H.-J., and Bischoff-Gauss, I.: Modeling haboob dust storms in large-scale weather and climate models, J. Geophys. Res.-Atmos., 121, 2090-2109, 2016. 
Párez, C., Haustein, K., Janjic, Z., Jorba, O., Huneeus, N., Baldasano, J. M., Black, T., Basart, S., Nickovic, S., Miller, R. L., Perlwitz, J. P., Schulz, M., and Thomson, M.: Atmospheric dust modeling from meso to global scales with the online NMMB/BSC-Dust model - Part 1: Model description, annual simulations and evaluation, Atmos. Chem. Phys., 11, 1300113027, https://doi.org/10.5194/acp-11-13001-2011, 2011.

Pearson, K. J., Lister, G. M. S., Birch, C. E., Allan, R. P., Hogan, R. J., and Woolnough, S. J.: Modelling the diurnal cycle of tropical convection across the "grey zone", Q. J. R. Meteorol. Soc., 140, 491-499, 2014.

Pope, R. J., Marsham, J. H., Knippertz, P., Brooks, M. E., and Roberts, A. J.: Identifying errors in dust models from data assimilation, Geophys. Res. Lett., 43, 9270-9279, 2016.

Provod, M., Marsham, J. H., Parker, D. J., and Birch, C. E.: A Characterization of Cold Pools in the West African Sahel, Monthly Weather Rev., 144, 1923-1934, 2016.

Prospero, J. M., Ginoux, P., Torres, O., Nicholson, S. E., and Gill, T. E.: Environmental characterization of global sources of atmospheric soil dust identified with the nimbus 7 total ozone mapping spectrometer (TOMS) absorbing aerosol product, Rev. Geophys., 40, 1002, https://doi.org/10.1029/2000RG000095, 2002.

Ridley, D. A., Heald, C. L., and Ford, B.: North African dust export and deposition: A satellite and model perspective, J. Geophys. Res., 117, D02202, https://doi.org/10.1029/2011JD016794, 2012.

Roberts, A. J. and Knippertz, P.: Haboobs: convectively generated dust storms in West Africa, Weather, 67, 311-316, 2012.

Roberts, A. J. and Knippertz, P.: The formation of a large summertime Saharan dust plume: Convective and synoptic scale analysis, J. Geophys. Res.-Atmos., 119, 1766-1785, 2014.

Roberts, A. J., Marsham, J. H., and Knippertz, P.: Disagreement in low-level moisture between (re)analyses over summertime West Africa, Mon. Weather Rev., 143, 1193-1211, 2015.

Roberts, A. J., Marsham, J. H., Knippertz, P., Parker, D. J., Bart, M., Garcia-Carreras, L., Hobby, M., McQuaid, J., Rosenberg, P., and Walker, D.: New Saharan wind observations reveal substantial biases in analysed dust-generating winds, Atmos. Sci. Lett., 18, 366-372, 2017.

Rodwell, M. J. J. and Jung, T.: Understanding the local and global impacts of model physics changes: An aerosol example, QJRMS, 1479-1497, 2008.

Sayer, A. M., Munchak, L. A., Hsu, N. C., Levy, R. C., Bettenhausen, C. and Jeong, M.-J.: MODIS Collection 6 aerosol products: Comparison between AQUA's e-Deep Blue, DarkTarget, and "merged" data sets, and usage recommendations, J. Geophys.Res.-Atmos., 119, 13965-13989, 2014.
Staniforth, A., White, A., Wood, N., Thuburn, J., Zerroukat, M., Cordero, E., Davies, T., and Diamantakis, M.: Unified Model Documentation Paper 015 Joy of U.M. 6.3-Model Formulation, Met Office, Exeter, UK, 2006.

Stein, T. R., Hogan, R. J., Hanley, K. E., Nicol, J. C., Lean, H. W., Plant, R. S., Clark, P. A., and Halliwell, C. E.: The ThreeDimensional Morphology of Simulated and Observed Convective Storms over Southern England, Mon. Weather Rev., 142, 3264-3283, 2014.

Stratton, R., Willet, M., Derbyshire, S., and Wong, R.: Convection Scheme Unified Model Documentation Paper 27, Met Office, Exeter, UK, 2009.

Terradellas, E., Basart, S., Benincasa, F., and Serradell, K.: Barcelona Dust Forecast Centre: Activity Report 2016, Barcelona Supercomputing Center, Barcelona, Spain, 2017.

Todd, M. C. and Cavazos-Guerra, C.: Dust aerosol emission over the Sahara during summertime from Cloud-Aerosol Lidar with Orthogonal Polarization (CALIOP) observations, Atmos. Environ., 128, 147-157, 2016.

Touma, J. S.: Dependence of the wind profile power law on stability for various locations, J. Air. Pollut. Control Assoc., 27, 863-866, 1977.

Tompkins, A. M., Cardinali, C., Morcrette, J.-J. and Rodwell, M.: Influence of aerosol climatology on forecasts of the African Easterly Jet. Geophys. Res. Lett., 32, L10801, https://doi.org/10.1029/2004GL022189, 2005.

Trzeciak, T. M., Garcia-Carreras, L., and Marsham, J. H.: CrossSaharan transport of water vapor via recycled cold pool outflows from moist convection, Geophys. Res. Lett., 44, 15541563, 2017.

Wilkinson, J.: Unified Model Documentation Paper 26 The LargeScale Precipitation Parametrization Scheme, Met Office, Exeter, UK, 2012.

Woodage, M. J., Slingo, A., Woodward, S., and Comer, R. E.: U.K. HiGEM: Simulations of Desert Dust and Biomass Burning Aerosols with a high-resolution atmospheric GCM, J. Climate, 23, 1636-1659, 2010.

Woodward, S.: Mineral dust in HadGEM2, Hadley Centre Technical Note, 87, 2011.

Wu, Y., de Graaf, M., and Menenti, M.: Improved MODIS Dark Target aerosol optical depth algorithm over land: angular effect correction, Atmos. Meas. Tech., 9, 5575-5589, https://doi.org/10.5194/amt-9-5575-2016, 2016. 